\title{
Do Jumps Matter in Both Equity Market Returns and Integrated Volatility: A Comparison of Asian Developed and Emerging Markets
}

\author{
Hassan Zada ${ }^{1}$ (D) Arshad Hassan ${ }^{1}$ and Wing-Keung Wong ${ }^{2,3,4, *(\mathbb{D})}$ \\ 1 Department of Management Sciences, Capital University of Science and Technology (CUST), \\ Islamabad 44000, Pakistan; hassanzaada@gmail.com (H.Z.); aarshad.hasan@gmail.com (A.H.) \\ 2 Department of Finance, Fintech Center, and Big Data Research Center, Asia University, \\ Taichung City 41354, Taiwan \\ 3 Department of Medical Research, China Medical University, Taichung City 40402, Taiwan \\ 4 Department of Economics and Finance, The Hang Seng University of Hong Kong, Hong Kong 999077, China \\ * Correspondence: wong@asia.edu.tw
}

check for updates

Citation: Zada, Hassan, Arshad Hassan, and Wing-Keung Wong. 2021. Do Jumps Matter in Both Equity Market Returns and Integrated Volatility: A Comparison of Asian Developed and Emerging Markets. Economies 9: 92. https://doi.org/ 10.3390/economies 9020092

Academic Editor:

Hans-Eggert Reimers

Received: 31 March 2021

Accepted: 10 June 2021

Published: 16 June 2021

Publisher's Note: MDPI stays neutral with regard to jurisdictional claims in published maps and institutional affiliations.

Copyright: (c) 2021 by the authors. Licensee MDPI, Basel, Switzerland. This article is an open access article distributed under the terms and conditions of the Creative Commons Attribution (CC BY) license (https:/ / creativecommons.org/licenses/by/ $4.0 /)$.

\begin{abstract}
In this paper, we examine whether jumps matter in both equity market returns and integrated volatility. For this purpose, we use the swap variance $(\mathrm{SwV})$ approach to identify monthly jumps and estimated realized volatility in prices for both developed and emerging markets from February 2001 to February 2020. We find that jumps arise in all equity markets; however, emerging markets have more jumps relative to developed markets, and positive jumps are more frequent than negative jumps. In emerging markets, the markets with average volatility earn higher returns during jump periods; however, highly volatile markets earn higher returns during jump periods in developed markets. Furthermore, markets with low continuous returns and high volatility are more adversely affected during periods of negative jumps. The average ratio of jump variations to total variation shows considerable variations due to jumps. Integrated volatility is high during periods of negative jumps, and this pattern is consistent in both developed and emerging markets. Moreover, the peak volatility of stock markets is observed during periods of crises. The implication of this study is useful in the asset pricing model, risk management, and for individual investors and portfolio managers for both developed and emerging markets.
\end{abstract}

Keywords: jumps identification; swap variance; integrated volatility; realized volatility

JEL Classification: C58; G12; G15; D53; C58

\section{Introduction}

Over the past decade, integrated volatility and jumps in asset pricing have attracted particular attention in the literature of finance, and their importance is prominent (Brownlees et al. 2020; Buncic and Gisler 2017). As per the efficient market hypothesis $(\mathrm{EMH})$, the stock market responds to the arrival of new information, leading to changes in returns and volatility of the stock market prices (Duangin et al. 2018). However, sometimes there are abnormal movements or large discontinuous changes in stock prices, which are infrequent but large; these extreme movements are known as jumps, associated with the arrival of unexpected new information (Ferriani and Zoi 2020; Jiang and Zhu 2017; Sun and Gao 2020). Accordingly to Bajgrowicz et al. (2016), jumps are related to macroeconomic news, prescheduled company-specific announcements, and news reports that included a variety of unscheduled and uncategorized events. The vast majority of news does not cause price jumps, but it may give rise to a market reaction in the form of bursts of volatility. Merton (1976) first introduced price jumps in his seminal paper, starting an extensive strand of literature in asset pricing and financial econometrics. Jumps identification has profound implications in risk management, asset pricing, valuation of derivatives, 
and portfolio allocation (Aït-Sahalia 2004; Bajgrowicz et al. 2016; Brownlees et al. 2020; Odusami 2021; Zhang et al. 2020).

Odusami (2021) stated that it is essential to include jumps in financial models for managing the risk in the portfolio because jumps bring movements in asset prices; therefore, risk premia should be accounting for jumps along with continuous sample path variance. This study has observed asymmetry in the distribution of jumps, with a higher magnitude of negative jumps than positive jumps. The implication of their study is that jump risk is non-diversifiable. Therefore, when pricing assets, investors should account for risk premia, and when selecting policy weights in their portfolios, they should consider the determinants of jump risks. Zhang et al. (2020) documented that in China, most of the listed companies are owned by the state and a limited portion of shares are available for trading in the stock market. Therefore, the Chinese stock market is highly susceptible to speculation. Furthermore, due to the increasing role of domestic and foreign institutions, stock market movements are still primarily driven by noise traders; that is, retail investors. Therefore, more jumps could be expected in emerging markets such as the Chinese stock market than in the developed stock markets.

The importance of jumps is illustrated in some early studies, including by Ait-Sahalia (2004), Aït-Sahalia and Hurd (2015), Amaya and Vasquez (2011), Nguyen and Prokopczuk (2019), Buncic and Gisler (2017), Carr and Wu (2003), Duangin et al. (2018), Dutta et al. (2020), Eraker et al. (2003), Ferriani and Zoi (2020), Jiang and Oomen (2008), Jiang and Yao (2013), Jiang and Zhu (2017), Pan (2002), and Wright and Zhou (2009).

Pan (2002) shows evidence that investors demand a higher risk premium for taking the risk associated with price jumps. Eraker et al. (2003) found strong evidence for jumps in returns and jumps in volatility. Jumps in the volatility model significantly increase implied volatility in the money and out of the money options than models having only jumps in returns. Carr and $\mathrm{Wu}$ (2003) state that to understand asset price behavior, it is necessary to determine whether the best model is based on a purely continuous process, a pure jump process, or a combination of both of these two processes. Ait-Sahalia (2004) comments that jumps play an important role in asset returns, diminishing marginal returns, currencies, and interest rates. Moreover, the decomposition of total risk into Brownian and jump components is very useful for portfolio allocation and risk management.

Jiang and Oomen (2008) document that jumps are an essential component of financial asset price dynamics. The arrival of unanticipated news or liquidity shocks often results in substantial and instantaneous revisions in the valuation of financial securities. Wright and Zhou (2009) explained that there is significant evidence of predictability in excess returns on various assets, and some of the predictability may be attributed to time-variation in the distribution of jump risk. They observed that jump risk measures could accurately predict future excess returns of the bond. Furthermore, the coefficient on the jump means it is statistically significant, implying that including jumps can increase the predictability of bond risk premia. The analysis has shown that root mean square prediction error can be reduced to $40 \%$ by including the jump mean in the model. Amaya and Vasquez (2011) suggest that positive jumps have a different effect on the future price of stocks than negative jumps. Positive jumps increase the prices of securities, and thus, a risk-averse investor prefers a positive over a negative jump. Therefore, stocks with negative jumps should earn a premium compared to stocks with positive jumps. Jiang and Yao (2013) stated that small and illiquid stocks have higher jump returns and the value premium is accounted for by the jumps. Jiang and Zhu (2017) using jumps as a proxy of informational shocks relaxed the requirements of planned event dates; therefore, they are not strictly related to events that are announced publicly. Jumps carry information that is beyond specific planned corporate events and bring large discontinued changes in the prices. Corradi et al. (2018) argued that considering the jump behavior improves the conditional variance forecasts of returns. Ferriani and Zoi (2020) noted that during phlegmatic market conditions, the relative contribution of jumps to total price variance is higher than during times of stress. Dutta et al. (2020) tested the presence of jumps in 
OVX and explored their role to predict crude oil price volatility. According to the findings, OVX has a jump behavior that varies over time. They warrant investors, policymakers, and academics accounting for the presence of jumps to develop more accurate asset pricing models and volatility prediction methods.

Baker et al. (2020) explored the possible explanations for the stock market's unusual reaction to the COVID-19 pandemic. Previous pandemics had a very mild impact on the US stock market, whereas the COVID-19 pandemic has had a much more substantial impact on the stock market than previous pandemics such as the Spanish flu. The evidence suggests that government restrictions on commercial activity and voluntary social distancing, operating with powerful effects in a service-oriented economy, are the primary reasons that the US stock market reacted so strongly to COVID-19 than to the previous pandemic. Sharif et al. (2020) examined the relationship between COVID-19, oil price volatility shock, the stock market, geopolitical risk, and economic policy uncertainty using the coherence wavelet method and wavelet-based Granger causality tests. It is found from the analysis that COVID-19 and oil price shocks have an impact on geopolitical risk levels, economic policy uncertainty, and stock market volatility over low-frequency bands.

Apergis and Apergis (2020) analyzed the impact of the COVID-19 pandemic on the returns and volatility of the Chinese stock market. For COVID-19, they used two proxies: the total confirmed cases and the total daily deaths. The analysis shows that COVID-19, as measured by two different proxies, has a significant negative impact on stock returns; however, when total deaths are used as a proxy, the negative impact on stock returns is more pronounced. COVID-19, on the other hand, has a positive and statistically significant effect on the volatility. The findings are important for understanding the stock market implications of the COVID-19 pandemic. Uddin et al. (2021) studied the impact of the COVID-19 pandemic on stock market volatility to see if economic strength could help mitigate the negative effects of the global pandemic. According to the findings, country-level economic characteristics and factors help to mitigate the volatility caused by the pandemic. Based on economic factors, policymakers may devise policies to combat stock market volatility and avoid financial crises in the future. Empirical results of Kostrzewski and Kostrzewska (2021) indicate that a model with a time-varying jump intensity and a jump prediction mechanism is useful in forecasting.

A comprehensive study is needed to cover the existing gap in the literature related to the jump studies. As stated by Kongsilp and Mateus (2017), most existing studies on jump behavior are based on the developed market, whereas Zhang et al. (2020) stated that there are very few studies on jump behavior in the emerging market. We have conducted this study to cover the gap; first, by identifying jumps in Asian developed and emerging markets and to compare both markets. Second, to study asymmetric behaviour of positive and negative jumps in returns of Asian developed and emerging markets and to compare both markets. Third, to study asymmetric behavior of positive and negative jumps in integrated volatility of Asian emerging and developed markets and to compare their results.

This study aims to examine whether jumps matter in equity market returns and integrated volatility in the context of Asian developed and emerging equity markets.

The contribution of this paper is as follows. First, we apply the swap variance (SwV) test developed by Jiang and Oomen (2008) to identify monthly jumps in Asian developed markets and Asian emerging markets. The $\mathrm{SwV}$ test is similar in purpose to the bipower variation (BPV) test developed by Barndorff-Nielsen and Shephard (2006) but with different logic and properties. The BPV test identifies jumps by comparing RV to a jump robust variance measure. In contrast, the $\mathrm{SwV}$ test identifies jumps by comparing RV to a jump-sensitive variance measure involving higher-order moments of returns, making it more powerful in many circumstances. Moreover, the $\mathrm{SwV}$ jump test explicitly considers market microstructure noise and can be applied to daily data (Jiang and Oomen 2008; Jiang and Zhu 2017). Second, we examine the role of positive jumps and negative jumps in equity returns individually and collectively. Third, we identify the role of positive and 
negative jumps in integrated volatility separately and jointly. The study further provides insight into the varying dynamics of jumps in developed and emerging markets of Asia. The findings in our study provide insights to academics, practitioners, and policymakers on the asymmetric effect of jumps in equity market returns and integrated volatility in the context of developed and emerging markets.

The rest of the paper is organized as follows. Section 2 is a methodological review of the swap variance jump, Section 3 explains the theory, Section 4 describes the data and methodology, Section 5 provides empirical results and findings, Section 6 discusses the results with previous studies, whereas Section 7 concludes the study and provides future directions.

\section{Methodological Review of Swap Variance Jump}

Andersen et al. (2001, 2003b) proposed realized volatility (RV). RV is a model-free and error-free estimator of integrated volatility in the absence of noise and jumps. BarndorffNielsen and Shephard (2003) extended RV and introduced a generalized form of realized volatility known as realized power variation (RPV). Based on RPV, Barndorff-Nielsen and Shephard (2004) introduce realized bi-power variation (BPV), which is a partial generalization of quadratic variation. BPV has the same robustness property as RPV. However, $\mathrm{BPV}$ also estimates the integrated variance in stochastic volatility models. In this way, BPV provides a model-free and consistent alternative to realized variance. Barndorff-Nielsen and Shephard (2004) also introduced the generalized form of bi-power variation called tri-power variation (TPV). BPV was an unbiased estimator of integrated volatility in the presence of jumps, but it is subject to an upward bias in a finite sample. TPV is more efficient than BPV but also more vulnerable to market microstructure noise of high-frequency data.

Eraker et al. (2003) developed a likelihood-based estimation method and analyzed jumps in returns and jumps in volatility in the S\&P 500 and Nasdaq 100 index. Empirics shows strong evidence for jumps in returns and jumps in volatility. Andersen et al. (2003a) developed a non-parametric technique to measure continuous sample path variation and discontinuous (the jump part) of a quadratic variation process separately. It was found that the jump component is less persistent than the continuous sample path. The coefficient of the jump component is highly significant in daily, weekly, and quarterly forecast horizons. This study shows that financial asset allocation, risk management, and derivatives pricing can be improved by separating the model for continuous and jump components.

Carr and Wu (2003) argued that it is essential to know whether it is the best model by using a purely continuous model, a pure jump process, or a combination of both of these two processes to understand asset prices' behavior. They developed a method to differentiate between these processes. They examined these processes using market prices of at-the-money (ATM) and out-of-the-money (OTM) options as the option maturity date approaches the valuation date. The speed of convergence varies across these possibilities when ATM and OTM options prices converge to zero as the maturity date approaches zero. They identified the type of asset price process by examining the convergence speed of the option prices. In a continuous process, there are low chances that the underlying asset prices will jump by a large amount over a short time interval. So there is a small possibility that the OTM option will move in the money. Whereas, in the jump process, there are high chances that the underlying asset prices can jump into the money in a short period. The behavior of these two types of processes is different for option prices in the short term because these two processes are difficult to distinguish from a discretely sampled path.

Johannes (2004) explores the statistical and economic role of jumps in continuoustime interest rate models. The results show that jumps are substantial both economically and statistically. Statistically, the presence of jumps means that models of diffusion are misspecified. Diffusion models ignore jumps and are incorrectly specified because the tail behavior of interest rate changes cannot be accurately captured. To quantify the statistical role of jumps in interest rates, he proposed and estimated a non-parametric jump-diffusion model. 
Aït-Sahalia (2004) uses maximum likelihood statistical-based methods to disentangle volatility from jumps accurately. He decomposes total noise into a continuous Brownian part and a discontinuous jump part. The Levy process is the sum of three independent Levy processes, which are a continuous component (Brownian motion), a component of big jumps in the form of a compound Poisson process with jump size larger than one, and a component of small jumps in the form of a pure martingale jump with jump size smaller than one. In this paper, Ait-Sahalia separated the Brownian component from the big jumps component and disentangled the Brownian component from the small jumps components.

Barndorff-Nielsen and Shephard (2004) concluded that the probability limit of the bipower estimator does not change by adding jumps to the SV model, meaning that realized variance can be combined with realized bi-power variation to estimate the quadratic variation of the jump component (the difference between realized variance and realized bi-power variation). This method separates quadratic variation into its continuous and jump components. Barndorff-Nielsen and Shephard (2006) propose two tests of jumps identification. One is the difference, and the second measure is the ratio of realized BPV and realized quadratic variation. They build the jump test on the idea of bi-power variation (BPV) provided by Barndorff-Nielsen and Shephard (2004) and Back (1991) that the sum of squared returns, a measure of variations in asset prices, is based on the quadratic variation process.

Lee and Mykland (2008) proposed a jump detection technique and conducted an empirical study on US equity markets. It found that more frequent jumps are observed in individual equity returns, and their size is larger than the index returns. In individual stocks, jumps are associated with company-specific news, i.e., scheduled earnings announcements and unscheduled news. Therefore, with earnings announcements, other firm-specific news is to be incorporated for option pricing. Whereas in the index, jumps occur because of general market news, i.e., Federal Open Market Committee (FOMC) meetings and macroeconomic reports. Therefore, general market news is to be incorporated for index options.

Jiang and Oomen (2008) established a non-parametric test to identify jumps in stock prices, known as the swap-variance $(\mathrm{SwV})$ approach. They built their test from the concept of Neuberger's (1994) variance swap replication strategy-a short position in the log contract plus a continuously rebalanced long position in the swap contract. The profit/loss of such a replication strategy will accumulate to an amount proportional to the variance realized (RV) and, as such, allows the swap contract to be perfectly replicated. Such a strategy fails, though, with jumps, and the realized jumps fully determine the replication error. The accumulated difference between simple returns and log returns is calculated-a quantity called "swap variance" — and compared to RV.

The difference will be indistinguishable from zero when jumps are absent, but when jumps are present, it will reflect the variance swap replication error, which in turn, lends its power to detect jumps. This test is similar in purpose to Barndorff-Nielsen and Shephard's (2006) bi-power variation test, but with different underlying logic and properties. By contrasting RV to a jump robust variance measure, the BPV test identifies jumps. By comparing RV to a jump-sensitive variance measure involving higher-order moments of return, the SwV test identifies jumps, making it more powerful in many circumstances. They conducted extensive simulations to examine the performance of the $S_{w} V$ test and compared their results with the bi-power variation test. The results indicate that the SwV jump test performs well and is a useful addition to the bi-power variation test.

\section{Theory}

This study uses the theory of efficient capital market theory developed by Fama (1970) and others to explain three types of efficiency, namely, the weak form, the semi-strong form, and the strong form of efficiency known as the efficient market hypothesis (EMH). It states that security prices fully reflect all relevant information, eliminating arbitrage opportunities and bringing stock markets towards efficiency. The weak form of efficiency states that 
investors cannot earn an excess return based on past prices, returns, and trading volumes. In the semi-strong form of efficiency, the relevant information is publicly available information which states that investors cannot earn an excess return on information based on annual reports and news from media. In a strong form of efficiency, both past information and publicly available information are irrelevant for investors to earn excess returns.

There are, however, abnormal movements or large discontinuous changes in empirical stock analysis that are infrequent but large; these extreme movements are known as jumps and associated with the arrival of unexpected new information. (Ferriani and Zoi 2020; Jiang and Zhu 2017; Sun and Gao 2020). Jiang and Zhu (2017) define stock price jumps as a proxy of large information shocks, and large discontinued changes in stock prices called jumps or stock price jumps.

There are several advantages to using stock price jumps as a proxy for large information shocks; for example, studies on corporate events require event dates. The approach of using stock price jumps as a proxy for large information shocks, on the other hand, relaxes the requirements of event dates and is not limited to only publicly announced events. Private information, such as insider trading, can cause stock price changes. Jumps capture all types of information, whether it is public or private (Jiang and Oomen 2008; Jiang and Yao 2013; Jiang and Zhu 2017).

\section{Data and Methodology}

\subsection{Data}

We use the daily data of four developed and six emerging equity markets of Asia from February 2001 to February 2020. The Asian developed markets include Australia (S\&P ASX), Hong Kong (Hang Seng index), Japan (Nikkei225 index), and New Zealand (NZX 50 index). Moreover, the emerging Asian equity markets include China (Shanghai Composite index), India (Nifty 50 index), Indonesia (JKSE index), Pakistan (KSE-100 index), Thailand (SET Index), and Sri Lanka (CSE All index). We use the Morgan Stanley Capital International (MSCI) classification to segregate the developed and emerging markets. The data of these equity indices are taken from the Thomson Reuters DataStream.

\subsection{Methodology}

There are various methods to identify statistically significant jumps. The methods can be grouped into five categories: first, jump tests based on bi-power variation include the tests developed by Andersen et al. (2007, 2012), Barndorff-Nielsen and Shephard (2004, 2006), Corsi et al. (2010), and Huang and Tauchen (2005); second, techniques based on higher-order variation include the techniques developed by Ait-Sahalia and Jacod (2009) and Podolskij and Ziggel (2010); third, jump tests based on returns include the tests developed by Lee and Hannig (2010) and Lee and Mykland (2008); fourth, tests based on swap variance include tests developed by Jiang and Oomen (2008); fifth, jump tests that mitigate the impact of microstructure noise include the tests developed by Ait-Sahalia and Jacod (2012) and Lee and Mykland (2012).

In this study, the jumps are estimated through the swap variance (SwV) jump identification method proposed by Jiang and Oomen (2008). The jump test statistic, $\mathrm{J}_{\mathrm{t}}$, at time $\mathrm{t}$ is given in the following equation under the null hypothesis of no jump:

$$
\mathrm{J}_{\mathrm{t}}=\frac{\mathrm{BPV}_{\mathrm{t}}}{\mathrm{M}^{-1} \sqrt{\hat{\Omega}_{\mathrm{SwV}}}}\left(\frac{1-\mathrm{RV}_{\mathrm{t}}}{\mathrm{SwV}_{\mathrm{t}}}\right),
$$

where $\mathrm{J}_{\mathrm{t}}$ is Jiang and Oomen (2008) swap variance jump test statistics and $\mathrm{RV}_{\mathrm{t}}$ is the realized variance (Andersen et al. 2001), a measure of total volatility in asset prices calculated by summing daily squared returns filtered through an MA (1) process, that can be estimated by the following equation:

$$
R V_{t}=\sum_{i=1}^{M-1}\left(r_{i}\right)^{2}
$$


where $R V_{t}$ is monthly realized volatility and $r_{i}$ is the daily logarithmic return, and $B P V_{t}$ is the realized bi-power variation developed by Barndorff-Nielsen and Shephard (2004) to capture the continuous component of total variation, and is calculated as:

$$
\mathrm{BPV}_{\mathrm{t}}=\frac{\pi}{2}\left(\frac{\mathrm{M}}{\mathrm{M}-1}\right) \sum_{\mathrm{i}=2}^{\mathrm{M}}\left|\mathrm{r}_{\mathrm{i}}\right|\left|\mathrm{r}_{\mathrm{i}-1}\right|,
$$

where $\mathrm{BPV}_{\mathrm{t}}$ is the monthly bi-power variation and $\mathrm{SwV}_{\mathrm{t}}$ is swap variance and calculated as follows:

$$
\mathrm{SwV}_{\mathrm{t}}=2 \sum_{\mathrm{i}=1}^{\mathrm{M}}\left(\mathrm{R}_{\mathrm{i}}-\mathrm{r}_{\mathrm{i}}\right)
$$

where $\mathrm{SwV}_{\mathrm{t}}$ is the monthly swap variance, $R_{\mathrm{i}}$ is simple return, and $\hat{\Omega}_{\mathrm{SwV}}$ is estimated by the following equation:

$$
\hat{\Omega}_{\mathrm{SwV}}=\frac{\mu_{6}}{9} \mu_{6 / 4}{ }^{-4} \frac{\mathrm{M}^{3}}{\mathrm{M}-3} \sum_{\mathrm{i}=1 \mathrm{k}=0}^{\mathrm{M}} \prod^{3}\left|\mathrm{r}_{\mathrm{i}-\mathrm{k}}\right|^{3 / 2}
$$

in which the value of $\frac{\mu_{6}}{9} \mu_{6 / 4}{ }^{-4}=3.05$ (Maneesoonthorn et al. 2020), $\mathrm{M}$ is the number of equity market price observations per month with 22 observations per month, and $r_{i}$ denotes the logarithmic returns of equity market prices.

In addition, the total numbers of months having total jumps, and positive and negative jumps are given as follow:

$$
\begin{gathered}
\text { Number of days having jumps }=\sum_{\mathrm{i}=1}^{\mathrm{T}}\left(|\mathrm{Jt}|>\mathrm{c}_{\alpha}\right), \\
\text { Number of positive jumps days }=\sum_{\mathrm{i}=1}^{\mathrm{T}}\left(\mathrm{Jt}>\mathrm{c}_{\alpha}\right), \\
\text { Number of negative jumps days }=\sum_{\mathrm{i}=1}^{\mathrm{T}}\left(\mathrm{Jt}<-\mathrm{c}_{\alpha}\right),
\end{gathered}
$$

where $c_{\alpha}$ is the critical value at the $5 \%$ significance level, which is 1.645 and the percentage of the month having jumps relative to the total number of the months is computed as under:

$$
\text { Percentage of months having jumps }=\frac{\text { Number of jump days }}{\text { Total number of days }} * 100 .
$$

We note that the estimated value of $\mathrm{J}_{\mathrm{t}}$ being greater than 1.645 indicates the presence of jumps at a significance level of $5 \%$.

\subsection{Integrated Volatility Due to Jump Component}

Barndorff-Nielsen and Shephard $(2004,2006)$ developed robust jump estimators to capture only the continuous component of quadratic variation known as realized bipower variation (BPV) and tri-power variation (TPV). BPV is an unbiased estimator of integrated volatility in the presence of jumps, but it is subject to an upward bias in a finite sample. Thereby, TPV is more efficient than BPV. Since RV estimates both continuous and discontinuous (jump) components of quadratic variation, while BPV and TPV capture only the continuous component, the jump component can be identified simply by the 
difference of RV and BPV (Barndorff-Nielsen and Shephard 2004, 2006), or RV and TPV (Andersen et al. 2007).

This study uses the method developed by Andersen et al. (2007) to separate the variation due to the monthly jump component and the continuous components by using volatility measures RV and tri-power variation (TPV). Variations due to the jump component are estimated as follows:

$$
\mathrm{JV}_{\mathrm{t}}=\mathrm{RV}_{\mathrm{t}}-\mathrm{TPV}_{\mathrm{t}}
$$

where tri-power variation (TPV) is given as follows:

$$
\mathrm{TPV}_{\mathrm{t}}=\left(2^{\frac{1}{3}} \frac{\gamma\left(\frac{5}{6}\right)}{\gamma\left(\frac{1}{2}\right)}\right)^{-3} \sum_{\mathrm{i}=3}^{\mathrm{M}-1}\left|\mathrm{r}_{\mathrm{i}}\right|^{2 / 3}\left|\mathrm{r}_{\mathrm{i}-1}\right|^{2 / 3}\left|\mathrm{r}_{\mathrm{i}-2}\right|^{\frac{2}{3}} .
$$

The ratio of jump variation to total variation is calculated as:

$$
\text { The ratio of jump variation to total variations }=\frac{J_{t}}{R V_{t}} .
$$

\subsection{Hypotheses}

The hypotheses of this study are:

Hypothesis 1. Jumps occur more frequently in emerging markets as compared to developed markets.

Hypothesis 2. Returns during positive jumps periods are larger than returns during non-jump periods and more pronounced in emerging markets as compared to developing markets.

Hypothesis 3. Integrated volatility during the negative jumps period is larger than integrated volatility during the positive jumps period and this pattern is more pronounced in emerging markets than developed markets.

Hypothesis 4. Total realized volatility consists of a significant portion of jump volatility.

\section{Empirical Analysis}

Table 1 shows the number of months in which jumps have been identified. In the developed markets, it is observed that the Hang Seng index has the maximum number of jumps. The jumps have been identified in 71 months out of 229 months being studied, including 43 positive jumps and 28 negative jumps. Furthermore, the minimum number of jumps in the developed markets are identified in NZX50, which are in 56 months out of a total of 229 months. In these 56 months, 33 months have positive jumps, whereas 23 months have negative jumps.

In the emerging markets, the maximum number of jumps are identified in the CSE All index, which has jumps in 100 months with 63 positive jumps and 37 negative jumps. However, the minimum number of jumps is 63 for the Nifty 50 index, including 40 positive jumps and 23 negative jumps.

It is concluded from Table 1 that, on average, the developed markets have fewer jumps as compared with the emerging markets. Similarly, positive and negative jumps also arise more frequently in the emerging markets in comparison with the developed markets. Furthermore, on average, the tendency of a larger number of positive jumps relative to negative jumps occurs in both developed and emerging markets. 
The possible justifications of the occurrence of more jumps in the emerging markets relative to the developed markets could be the riskier and more volatile nature of the emerging markets due to political instability, poor corporate governance, thin structure of the markets, lack of liquidity, high inflation rate, deflation or currency devaluations, interest rate risk, and high cross-border cash flows. All these factors hurt the economy and make the stock markets highly volatile, which leads to an increase in the tendency of jumps.

Table 1. Number of monthly jumps (provides the percentage and the number of months having SwV jump at $\alpha=0.05$ significance level).

\begin{tabular}{ccccccc}
\hline \multirow{2}{*}{ Markets } & \multicolumn{2}{c}{ Overall Jumps } & \multicolumn{2}{c}{ Positive Jumps } & \multicolumn{2}{c}{ Negative Jumps } \\
\cline { 2 - 6 } & $\begin{array}{c}\text { Number of } \\
\text { Jumps }\end{array}$ & $\begin{array}{c}\text { Percentage of } \\
\text { Jumps }\end{array}$ & $\begin{array}{c}\text { Number of } \\
\text { Jumps }\end{array}$ & $\begin{array}{c}\text { Percentage of } \\
\text { Jumps }\end{array}$ & $\begin{array}{c}\text { Number of } \\
\text { Jumps }\end{array}$ & $\begin{array}{c}\text { Percentage of } \\
\text { Jumps }\end{array}$ \\
\hline S\&P ASX 200 & 62 & $27.0742 \%$ & 33 & $14.4105 \%$ & 29 & $12.6638 \%$ \\
Hang Seng & 71 & $31.0044 \%$ & 43 & $18.7773 \%$ & 28 & $12.2271 \%$ \\
Nikkei225 & 56 & $24.4542 \%$ & 33 & $14.4105 \%$ & 23 & $10.0437 \%$ \\
NZX 50 & 58 & $25.3275 \%$ & 32 & $13.9738 \%$ & 26 & $11.3537 \%$ \\
Shanghai Compo & 93 & $40.6114 \%$ & 41 & $17.9039 \%$ & 52 & $22.7074 \%$ \\
Nifty50 & 63 & $27.5109 \%$ & 40 & $17.4673 \%$ & 23 & $10.0437 \%$ \\
JKSE & 67 & $29.2576 \%$ & 41 & $17.9039 \%$ & 26 & $11.3537 \%$ \\
KSE-100 & 73 & $31.8777 \%$ & 56 & $24.4542 \%$ & 17 & $7.4236 \%$ \\
SET Index & 77 & $33.6245 \%$ & 49 & $21.3974 \%$ & 28 & $12.2271 \%$ \\
CSE All & 100 & $43.6681 \%$ & 63 & $27.5109 \%$ & 37 & $16.1572 \%$ \\
\hline
\end{tabular}

The number of months with jumps, as identified in Table 1, is exhibited in the scatter plot (Figure 1), showing the total number of jumps, positive jumps, and negative jumps for all equity markets in the sample period from February 2001 to February 2020. It is reflected in Table 1 that the magnitude of some jumps is big whereas small for others. We set a cutoff point of +3 standard deviation and -3 standard deviation to distinguish small or average size jumps from big jumps. A jump with a magnitude greater than +3 standard deviation is considered a big positive jump. A jump with a magnitude between zero and +3 is considered a positive small or average size jump. Similarly, a jump with a magnitude less than -3 standard deviation is considered a big negative jump. A jump with a magnitude between zero and -3 is considered a negative average size or small jump.

It is observed from Figure 1 that in the context of developed markets, on average, the magnitude of big negative jumps is larger than the magnitude of big positive jumps. The same pattern is also observed for emerging markets as well. However, this pattern is much higher in emerging markets as compared with developed markets.

When considering small size jumps, we do not observe much of a difference in the magnitude of negative and positive jumps in the context of developed markets. However, on average, the magnitude of small negative jumps is slightly on the higher side of the small positive jumps in emerging markets.

This means that investors considered negative information more deeply than positive information. However, the depth of feeling is on the higher side in emerging markets. It may be due to the lack of confidence of investors in the information that may cause overreaction to negative information.

Table 2 presents descriptive statistics of continuous returns (r), returns during jump periods (Jr), returns during positive jump periods ( $\mathrm{Pjr}$ ), and returns during negative jump periods (Njr) for all of the equity markets. 

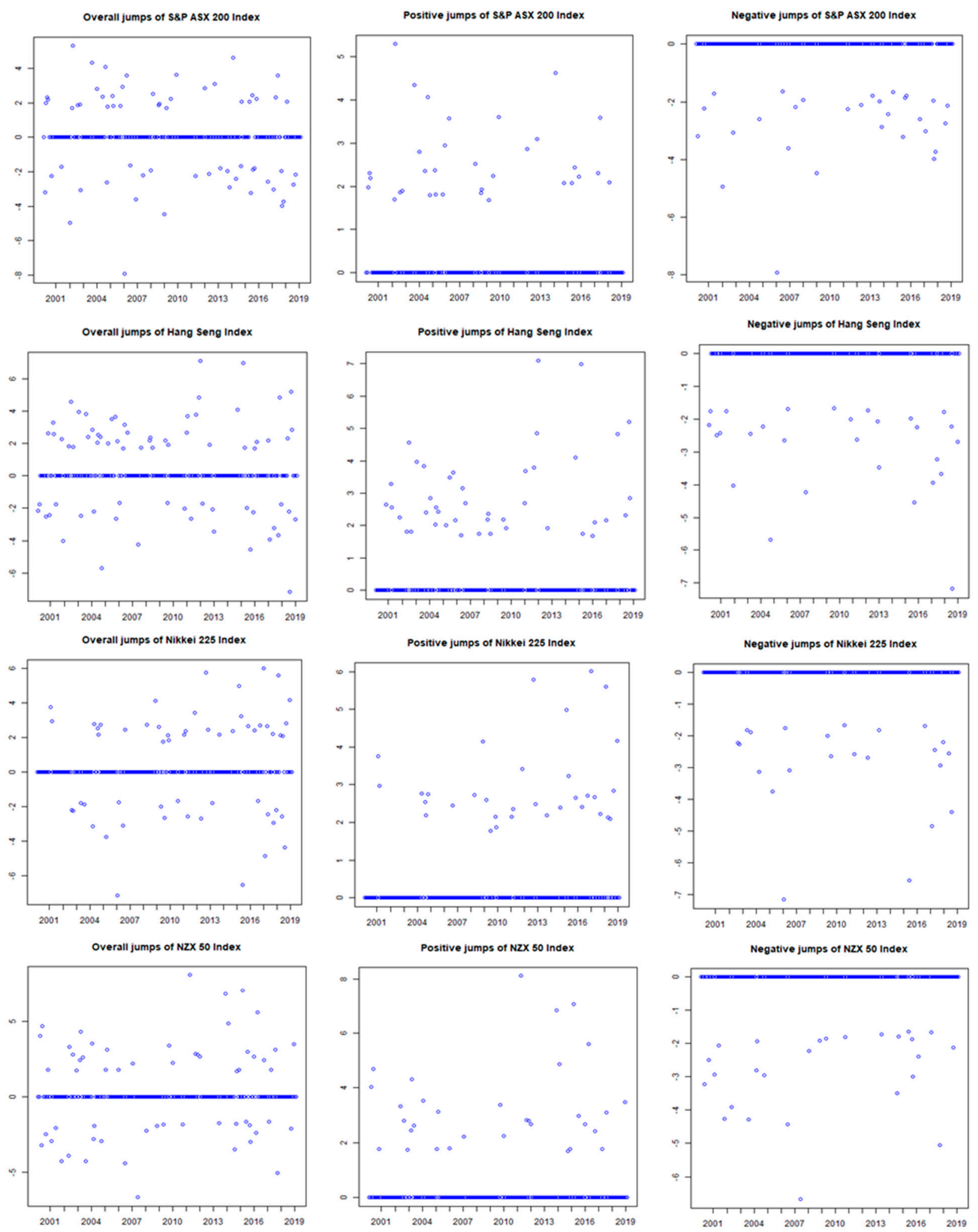

Figure 1. Cont. 

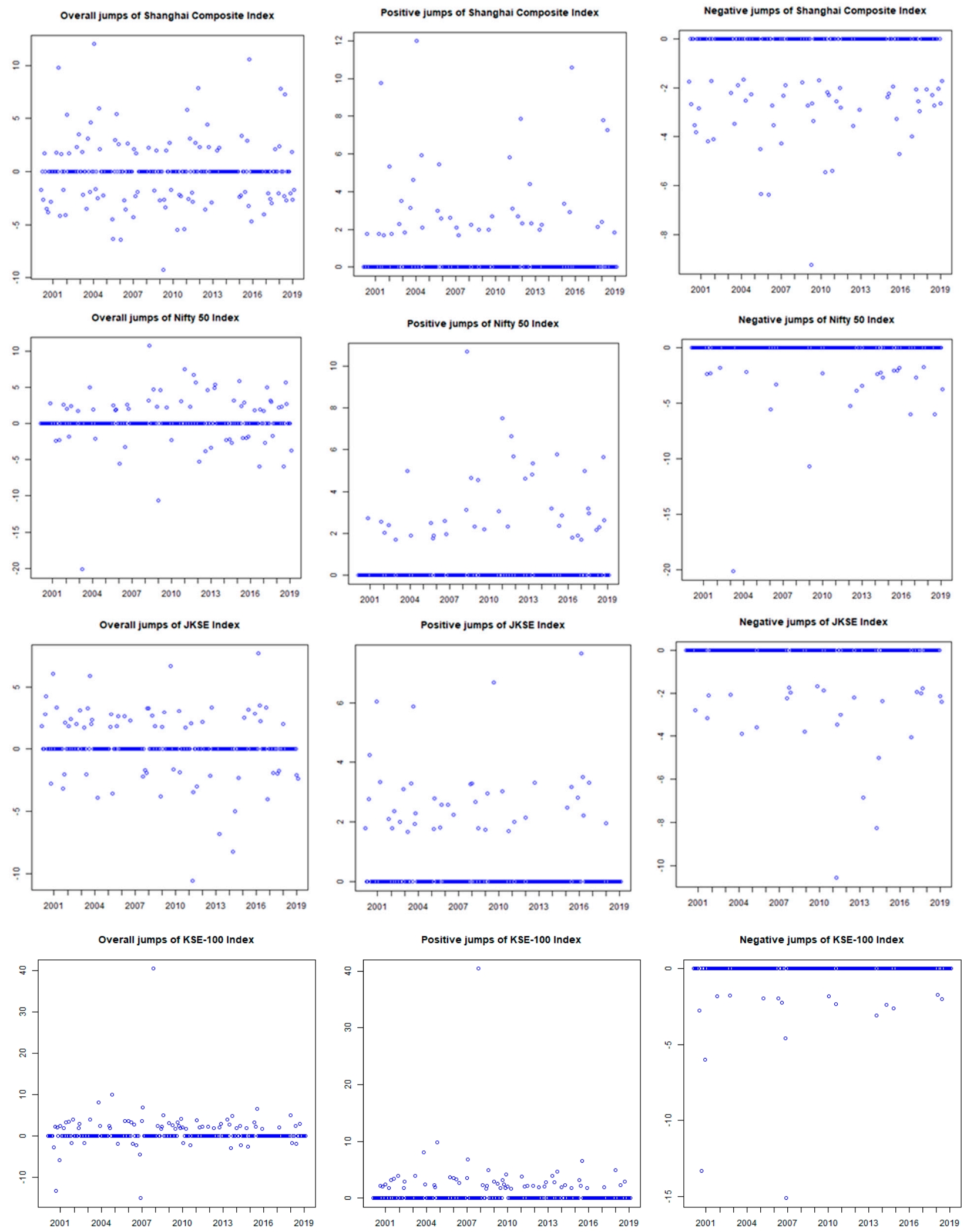

Figure 1. Cont. 

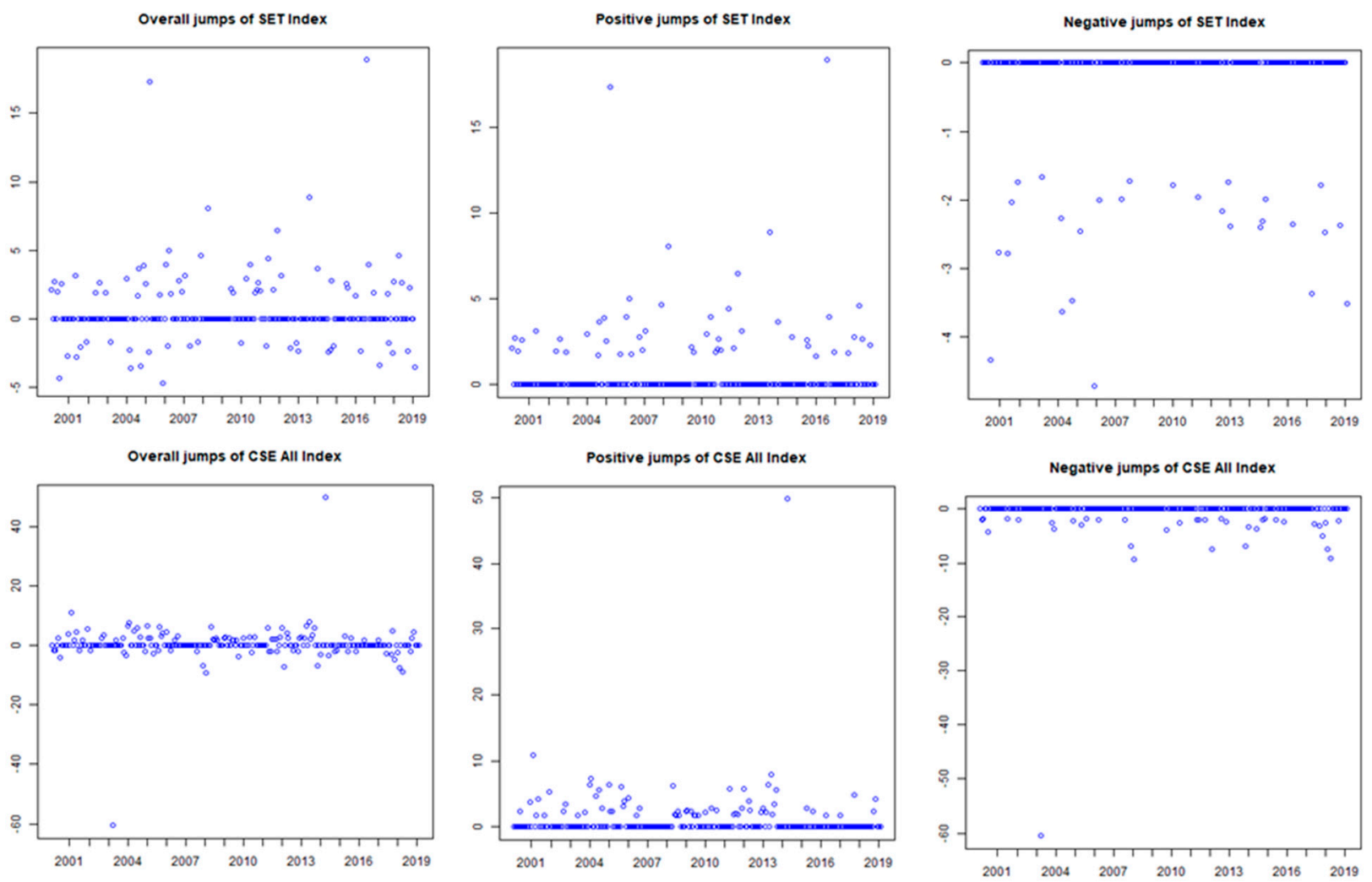

Figure 1. Number of months identified as having jumps.

Table 2 shows in developed markets, the NZX50 has earned higher continuous returns per month with minimum spread indicated by standard deviation, minimum, and maximum values followed by the S\&P ASX 200, so these markets are the most attractive for risk-averse investors. In comparison, the Nikkei225 has the lowest monthly continuous returns, followed by the Hang Seng with maximum spread indicated by standard deviation, minimum, and maximum values. Therefore, these markets are more volatile. For average returns during jump periods and average returns during positive jump periods, the Hang Seng and the Nikkei225 have the highest average returns per month, with maximum spread shown by standard deviation, minimum, and maximum values. Therefore, these markets are the most attractive markets for risk-taking investors. Whereas the NZX50 and the S\&P ASX 200 have the lowest returns during jump periods and lowest returns during positive jump periods with maximum spread indicated by standard deviation, minimum, and maximum values. It is observed from Table 2 that more volatile markets tend to earn larger jumps-based returns relative to less volatile markets. Furthermore, returns during positive jump periods are higher for a more volatile market than less volatile markets. Therefore, forecasting positive jumps plays an essential role for investors to earn larger returns. However, returns of more volatile markets like the Hang Seng and Nikkei225 are also more affected during negative jump periods relative to less volatile markets like the NZX50 and S\&P ASX. It is worth noting that among volatile markets, a market having low returns is much more vulnerable to negative jumps.

In emerging markets, the KSE-100, Shanghai composite, and SET index are more volatile markets (as measured by the standard deviation of continuous returns) relative to others. The Shanghai Composite has the lowest continuous return, and the KSE-100 has the largest continuous return per month. In emerging markets, returns during jump periods behave differently as compared with developed markets. In the context of emerging markets, a market with average volatility and average continuous return earns the highest return during positive jump periods. Its returns are the least vulnerable during negative jump periods, i.e., the Nifty50 index. However, highly volatile markets tend to earn high 
returns during positive jump periods, i.e., the Shanghai Composite and KSE-100. However, highly volatile markets with high continuous returns are less vulnerable to negative jumps, i.e., the KSE-100. In contrast, highly volatile markets with the lowest continuous returns are highly vulnerable to negative jumps, i.e., the Shanghai composite.

The results of Table 2 provide important insights to the investors in developed and emerging markets to earn the highest returns during jump periods. Investors can earn the highest returns during jump periods by investing in more volatile markets in developed markets. Investors in emerging markets can earn the highest returns during jump periods by investing in averagely volatile markets.

Table 2. Descriptive statistics of the returns based on the SwV jump test for February 2001-February 2020.

\begin{tabular}{|c|c|c|c|c|c|c|c|c|}
\hline $\begin{array}{c}\text { Stock } \\
\text { Markets }\end{array}$ & Jumps & Returns & Mean & $\begin{array}{l}\text { Standard } \\
\text { Deviation }\end{array}$ & Minimum & Maximum & Kurtosis & Skewness \\
\hline \multirow{4}{*}{$\begin{array}{c}\text { S\&P ASX } \\
200\end{array}$} & 229 & $\mathrm{r}$ & $0.2519 \%$ & $3.7637 \%$ & $-18.0921 \%$ & $9.7966 \%$ & 2.2341 & -0.9340 \\
\hline & 62 & $\mathrm{Jr}$ & $0.5962 \%$ & $4.2143 \%$ & $-8.2234 \%$ & $9.7263 \%$ & -0.7757 & -0.3974 \\
\hline & 33 & Pjr & $3.9866 \%$ & $1.5751 \%$ & $1.3901 \%$ & $9.7263 \%$ & 4.2457 & 1.4491 \\
\hline & 25 & Njr & $-3.8613 \%$ & $2.3048 \%$ & $-8.2234 \%$ & $-0.6418 \%$ & -1.0920 & -0.3721 \\
\hline \multirow{4}{*}{$\begin{array}{l}\text { Hang } \\
\text { Seng }\end{array}$} & 229 & $\mathrm{r}$ & $0.1648 \%$ & $5.8401 \%$ & $-25.4455 \%$ & $16.6256 \%$ & 1.5706 & -0.5375 \\
\hline & 71 & $\mathrm{Jr}$ & $1.0020 \%$ & $6.8924 \%$ & $-14.8779 \%$ & $15.7634 \%$ & -0.5823 & -0.3384 \\
\hline & 41 & Pjr & $5.9185 \%$ & $3.2722 \%$ & $1.5408 \%$ & $15.7634 \%$ & 1.2686 & 1.1281 \\
\hline & 24 & Njr & $-6.7389 \%$ & $3.0099 \%$ & $-12.0998 \%$ & $-2.2885 \%$ & -0.8648 & -0.4476 \\
\hline \multirow{4}{*}{ Nikkei225 } & 229 & $r$ & $0.1477 \%$ & $5.4474 \%$ & $-28.1743 \%$ & $13.2974 \%$ & 2.4333 & -0.8873 \\
\hline & 56 & $\mathrm{Jr}$ & $0.8550 \%$ & $6.0037 \%$ & $-12.3916 \%$ & $9.8655 \%$ & -0.6433 & -0.5415 \\
\hline & 32 & Pjr & $5.0995 \%$ & $2.6530 \%$ & $0.5388 \%$ & $9.8655 \%$ & -0.8728 & 0.2364 \\
\hline & 20 & $\mathrm{Njr}$ & $-5.7888 \%$ & $3.7833 \%$ & $-12.3916 \%$ & $-0.1800 \%$ & -1.1042 & -0.1636 \\
\hline \multirow{4}{*}{ NZX 50} & 229 & $\mathrm{r}$ & $0.6997 \%$ & $3.3810 \%$ & $-14.3129 \%$ & $8.3074 \%$ & 3.0201 & -1.1127 \\
\hline & 58 & $\mathrm{Jr}$ & $0.3917 \%$ & $4.6059 \%$ & $-12.6177 \%$ & $8.3074 \%$ & 0.4805 & -0.7939 \\
\hline & 31 & Pjr & $3.6863 \%$ & $1.9506 \%$ & $0.8938 \%$ & $8.3074 \%$ & -0.2181 & 0.7173 \\
\hline & 23 & Njr & $-4.0523 \%$ & $3.5320 \%$ & $-12.6177 \%$ & $-0.1199 \%$ & 0.6248 & -1.1078 \\
\hline \multirow{4}{*}{$\begin{array}{l}\text { Shanghai } \\
\text { Compos- } \\
\text { ite }\end{array}$} & 229 & $\mathrm{r}$ & $0.0815 \%$ & $7.6954 \%$ & $-28.2779 \%$ & $24.1212 \%$ & 1.8611 & -0.5456 \\
\hline & 93 & $\mathrm{Jr}$ & $-0.6212 \%$ & $8.6095 \%$ & $-25.6813 \%$ & $24.1212 \%$ & 1.2331 & -0.2843 \\
\hline & 38 & Pjr & $6.8995 \%$ & $5.1041 \%$ & $0.6321 \%$ & $24.1212 \%$ & 2.4278 & 1.4328 \\
\hline & 47 & Njr & $-7.0862 \%$ & $5.9507 \%$ & $-25.6813 \%$ & $-0.0324 \%$ & 3.5054 & -1.8611 \\
\hline \multirow{4}{*}{ Nifty 50} & 229 & $r$ & $0.6610 \%$ & $6.5050 \%$ & $-31.4173 \%$ & $24.7376 \%$ & 3.2013 & -0.6929 \\
\hline & 63 & $\mathrm{Jr}$ & $2.7033 \%$ & $7.1416 \%$ & $-10.8108 \%$ & $24.7376 \%$ & 0.1439 & 0.1544 \\
\hline & 39 & Pjr & $7.1890 \%$ & $4.5174 \%$ & $1.4348 \%$ & $24.7376 \%$ & 4.7044 & 1.5993 \\
\hline & 21 & $\mathrm{Njr}$ & $-5.5176 \%$ & $2.8865 \%$ & $-10.8108 \%$ & $-0.7725 \%$ & -0.2593 & -0.2174 \\
\hline \multirow{4}{*}{ JKSE } & 229 & $r$ & $0.9897 \%$ & $5.8087 \%$ & $-37.7197 \%$ & $16.4299 \%$ & 8.2715 & -1.2736 \\
\hline & 67 & $\mathrm{Jr}$ & $1.6460 \%$ & $8.0112 \%$ & $-37.7197 \%$ & $16.4299 \%$ & 7.5832 & -1.7574 \\
\hline & 39 & Pjr & $6.4671 \%$ & $3.9302 \%$ & $0.9253 \%$ & $16.4299 \%$ & -0.5821 & 0.6120 \\
\hline & 23 & $\mathrm{Njr}$ & $-6.2394 \%$ & $7.6569 \%$ & $-37.7197 \%$ & $-0.2483 \%$ & 13.7363 & -3.3510 \\
\hline \multirow{4}{*}{ KSE-100 } & 229 & $\mathrm{r}$ & $1.3069 \%$ & $7.0634 \%$ & $-44.8796 \%$ & $26.8315 \%$ & 8.3751 & -1.1923 \\
\hline & 73 & $\mathrm{Jr}$ & $3.9030 \%$ & $7.0027 \%$ & $-13.7559 \%$ & $26.8315 \%$ & 1.4439 & 0.1171 \\
\hline & 54 & Pjr & $6.8973 \%$ & $4.9518 \%$ & $0.0459 \%$ & $26.8315 \%$ & 4.6486 & 1.8307 \\
\hline & 15 & Njr & $-5.9510 \%$ & $3.9652 \%$ & $-13.7559 \%$ & $-0.3821 \%$ & -0.5902 & -0.5639 \\
\hline \multirow{4}{*}{ SET Index } & 229 & $r$ & $0.4797 \%$ & $5.9841 \%$ & $-35.5678 \%$ & $18.5915 \%$ & 5.9222 & -1.1025 \\
\hline & 77 & $\mathrm{Jr}$ & $1.4052 \%$ & $7.4367 \%$ & $-35.5678 \%$ & $18.5915 \%$ & 7.0311 & -1.5479 \\
\hline & 47 & Pjr & $5.7665 \%$ & $3.6945 \%$ & $0.6036 \%$ & $18.5915 \%$ & 2.4544 & 1.5202 \\
\hline & 26 & $\mathrm{Njr}$ & $-6.2224 \%$ & $6.7966 \%$ & $-35.5678 \%$ & $-0.1218 \%$ & 14.4451 & -3.3977 \\
\hline \multirow{4}{*}{ CSE All } & 229 & $r$ & $1.0549 \%$ & $6.3166 \%$ & $-16.6467 \%$ & $22.6313 \%$ & 1.4662 & 0.5101 \\
\hline & 100 & $\mathrm{Jr}$ & $2.5260 \%$ & $6.4478 \%$ & $-16.6467 \%$ & $20.6752 \%$ & 0.5568 & 0.1856 \\
\hline & 61 & Pjr & $6.3874 \%$ & $4.6555 \%$ & $0.3663 \%$ & $20.6752 \%$ & 0.8148 & 1.0713 \\
\hline & 34 & Njr & $-4.1298 \%$ & $3.3944 \%$ & $-16.6467 \%$ & $-0.5441 \%$ & 4.6596 & -1.9423 \\
\hline
\end{tabular}

Notes: There were some months in which positive jumps occurred, but the average monthly returns were negative, and some months in which negative jumps occurred but the average monthly returns were positive. All those jumps are excluded in descriptive stats. The descriptive in Table 2 shows only positive returns due to the positive jump component and negative returns due to the negative jump component. 
Table 3 summarizes integrated volatility, estimated using three volatility measures RV (measures total volatility), BPV (measures continuous component of quadratic variation), and TPV (also measures continuous component of quadratic variation). The mean, standard deviation, minimum and maximum values are all in terms of $10^{-3}$. It is observed from Table 3 that in terms of total realized volatility, the Nikkei225 and Hang Seng are more volatile markets among the developed market. Whereas among emerging markets, the Shanghai Composite shows maximum price fluctuations because it shows the highest average values of total integrated volatility. The SET index is the least volatile as its mean value of total integrated volatility is the lowest among all emerging markets. On average, emerging markets show higher integrated volatility than developed markets.

TPV is a better estimation technique of continuous components of quadratic variation than BPV as it understates the average integrated volatility and has the minimum standard deviation. This pattern is consistent across all markets. So jump-based volatility can be better estimated by the difference between RV and TPV.

Table 3. Descriptive statistics of integrated volatility measures: sample period February 2001-February 2020 (gives the descriptive statistics of integrated volatility measures. Mean, standard deviation, min, and max values are all in terms of $10^{-3}$ ).

\begin{tabular}{|c|c|c|c|c|c|c|c|}
\hline $\begin{array}{c}\text { Stock } \\
\text { Markets }\end{array}$ & $\begin{array}{l}\text { Volatility } \\
\text { Measures }\end{array}$ & Mean & $\begin{array}{l}\text { Standard } \\
\text { Deviation }\end{array}$ & Minimum & Maximum & Kurtosis & Skewness \\
\hline \multirow{3}{*}{$\begin{array}{c}\text { S\&P ASX } \\
200\end{array}$} & RV & 1.4529 & 1.0798 & 0.3504 & 5.8022 & 2.6574 & 1.6117 \\
\hline & $\mathrm{BPV}$ & 1.3487 & 1.0277 & 0.2972 & 6.0158 & 3.8336 & 1.7818 \\
\hline & TPV & 1.1553 & 0.8899 & 0.2314 & 5.3050 & 3.6988 & 1.7786 \\
\hline \multirow{3}{*}{ Hang Seng } & $\mathrm{RV}$ & 2.9317 & 2.1556 & 0.7857 & 11.0237 & 3.3522 & 1.8495 \\
\hline & BPV & 2.5073 & 1.9507 & 0.5426 & 9.1724 & 2.1121 & 1.6347 \\
\hline & TPV & 2.1091 & 1.6157 & 0.4468 & 8.1189 & 1.6944 & 1.5100 \\
\hline \multirow{3}{*}{ Nikkei225 } & RV & 3.4247 & 2.2574 & 0.7966 & 11.9135 & 1.7765 & 1.3347 \\
\hline & BPV & 2.9765 & 1.9456 & 0.6879 & 10.3380 & 1.2428 & 1.2221 \\
\hline & TPV & 2.4844 & 1.6604 & 0.5497 & 7.7575 & 0.7183 & 1.1457 \\
\hline \multirow{3}{*}{ NZX 50} & RV & 0.7701 & 0.4649 & 0.2971 & 2.2417 & 1.3827 & 1.4432 \\
\hline & $\mathrm{BPV}$ & 0.7297 & 0.4296 & 0.2327 & 2.1032 & 1.3560 & 1.3851 \\
\hline & TPV & 0.6335 & 0.3801 & 0.1796 & 1.9327 & 2.3059 & 1.5606 \\
\hline \multirow{3}{*}{$\begin{array}{l}\text { Shanghai } \\
\text { Composite }\end{array}$} & RV & 3.9949 & 3.5074 & 0.7680 & 17.2122 & 3.3589 & 1.8907 \\
\hline & BPV & 3.3525 & 3.1388 & 0.6017 & 14.9277 & 3.2916 & 1.9231 \\
\hline & TPV & 2.8382 & 2.6639 & 0.5087 & 12.3048 & 2.7118 & 1.8095 \\
\hline \multirow{3}{*}{ Nifty50 } & RV & 2.8283 & 2.3282 & 0.6211 & 13.4125 & 4.5987 & 2.0518 \\
\hline & BPV & 2.5720 & 2.2265 & 0.5642 & 11.7466 & 3.7416 & 1.9675 \\
\hline & TPV & 2.1730 & 1.9485 & 0.4271 & 10.0456 & 4.5098 & 2.0855 \\
\hline \multirow{3}{*}{ JKSE } & RV & 2.5999 & 1.9488 & 0.5215 & 9.0865 & 1.8538 & 1.5339 \\
\hline & BPV & 2.3813 & 1.8998 & 0.4648 & 9.5842 & 2.7272 & 1.7110 \\
\hline & TPV & 1.9888 & 1.5631 & 0.3861 & 7.9878 & 2.2781 & 1.5908 \\
\hline \multirow{3}{*}{ KSE-100 } & RV & 2.5977 & 2.0689 & 0.4544 & 10.7500 & 3.3322 & 1.7166 \\
\hline & BPV & 2.4521 & 2.2364 & 0.4140 & 12.3546 & 5.5840 & 2.2072 \\
\hline & TPV & 2.0947 & 2.0537 & 0.3541 & 11.6393 & 6.9485 & 2.4353 \\
\hline \multirow{3}{*}{ SET Index } & RV & 2.3601 & 1.7509 & 0.4492 & 7.7646 & 0.9081 & 1.2198 \\
\hline & BPV & 2.0880 & 1.6596 & 0.3018 & 8.2530 & 1.8726 & 1.4467 \\
\hline & TPV & 1.7931 & 1.5607 & 0.2368 & 7.8282 & 2.6481 & 1.6559 \\
\hline \multirow{3}{*}{ CSE All } & RV & 1.4006 & 1.5549 & 0.1686 & 8.2032 & 5.8931 & 2.3293 \\
\hline & BPV & 1.2959 & 1.4847 & 0.1510 & 8.1328 & 6.8381 & 2.3862 \\
\hline & TPV & 1.0759 & 1.2836 & 0.1110 & 6.9735 & 6.9342 & 2.4332 \\
\hline
\end{tabular}


To get a clearer idea of how volatility differs across the stock markets, we turn to Figures 2-11. They show the integrated volatility of the stock markets. It is noted that all individual stock markets have volatility during the financial crisis. Most of the stock markets also had their highest volatility in the 2008 crisis period. This is also in line with earlier discussion on jumps identification; in Figure 1, it can be observed that most of the jumps have occurred during crisis periods.

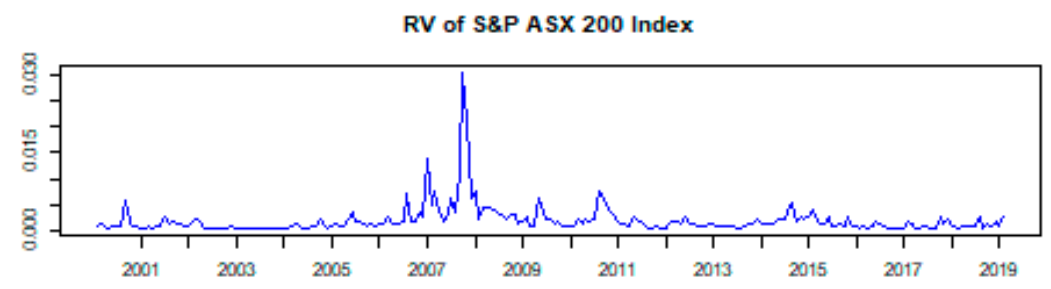

BPV of S\&P A SX 200 Index

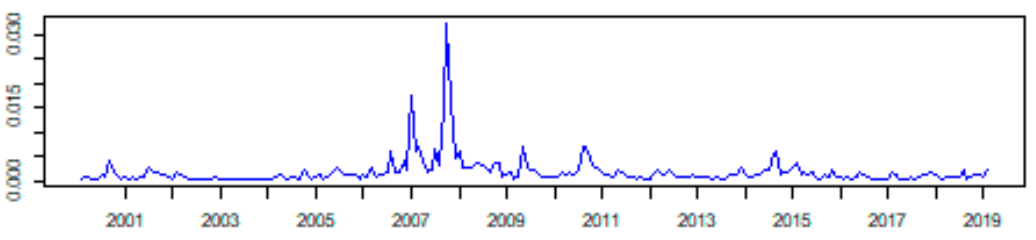

TPV of S\&P ASX 200 Index

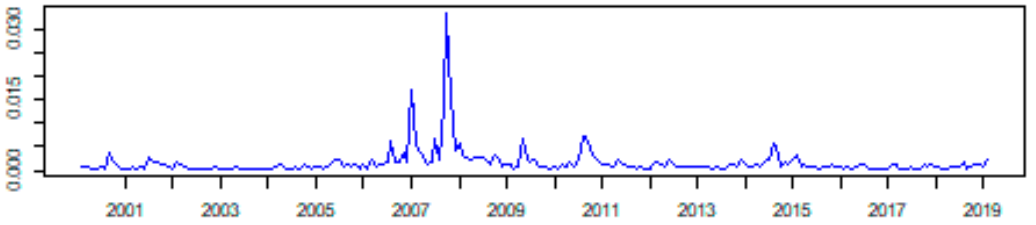

Figure 2. Integrated volatility measures-S\&P ASX 200. Notes: Figure 2 displays volatility of the S\&P ASX 200 across the sample period February 2001-February 2020 for realized volatility (RV), bi-power variation (BPV), and tri-power variation (TPV).

For the S\&P ASX 200 (Figure 2), Hang Seng (Figure 3), Nikkei225 (Figure 4), NZX 50 (Figure 5), JKSE (Figure 8, and SET Index (Figure 10), there seems to be little difference in terms of estimated volatility across the different volatility measures. However, in the Shanghai Composite (Figure 6), the highest volatility was in the 2015 period, a crisis period in China; however, a similar pattern is also observed during 2008. For the Nifty50 index (Figure 7), the peak was during 2008, but few spikes were recorded in 2003. The KSE100 (Figure 9) index is somewhat different from all others, which had major spikes in 2003, 2005, 2006, 2008, and at the beginning of 2009; all these periods were crisis periods in Pakistan. However, the CSE index (Figure 11) had major spikes during 2008 for all volatility measures. 
RV of Hang Seng Index

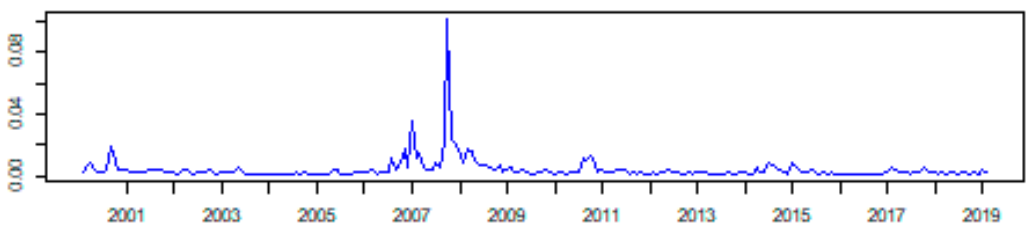

BPV of Hang Seng Index

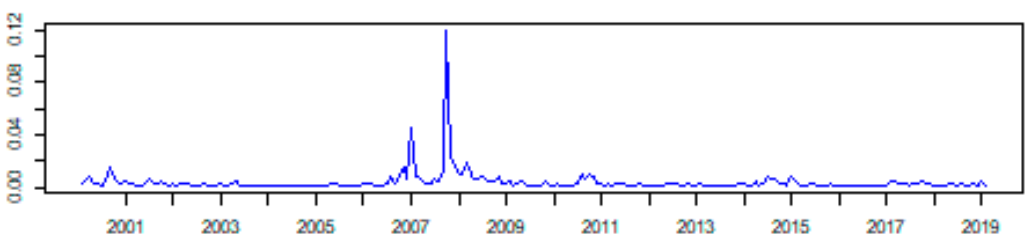

TPV of Hang Seng Index

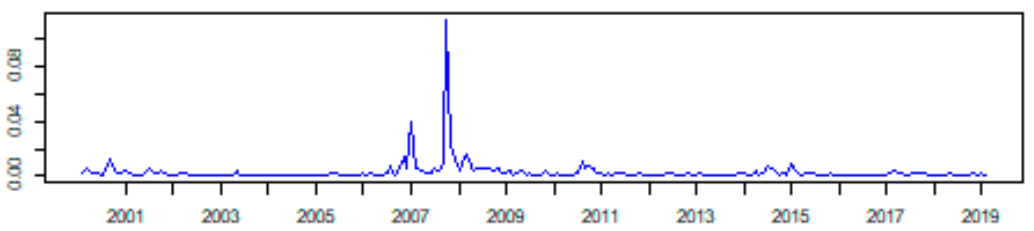

Figure 3. Integrated volatility measures-Hang Seng. Notes: Figure 3 displays the volatility movements of Hang Seng. See the notes in Figure 2.

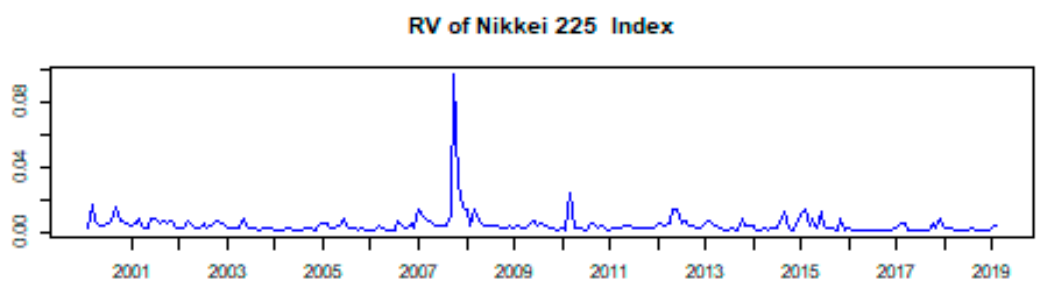

BPV of Nikkei 225 Index

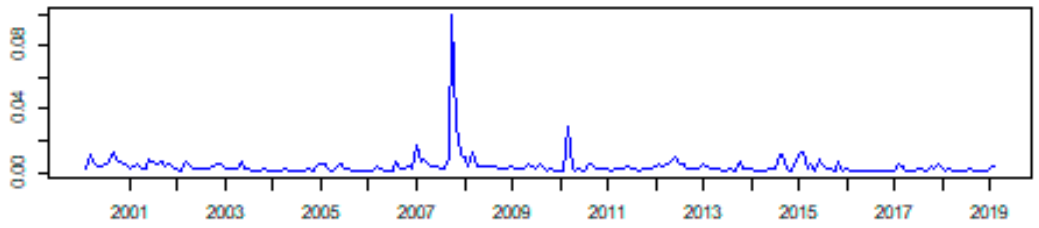

TPV of Nikkei 225 Index

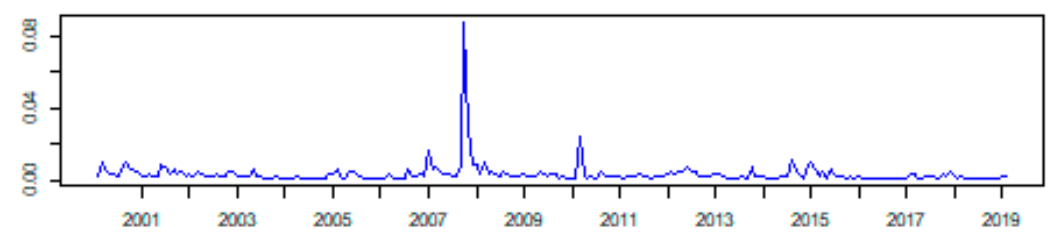

Figure 4. Integrated volatility measures-Nikkei225. Notes: Figure 4 displays the volatility movements of the Nikkei225. See the notes in Figure 2. 
RV of NZX 50 Index

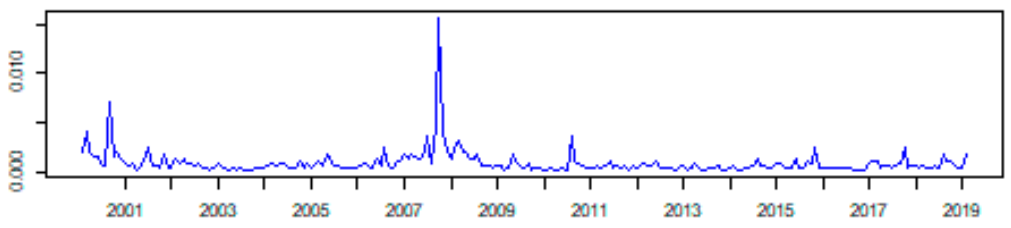

BPV of NZX 50 Index

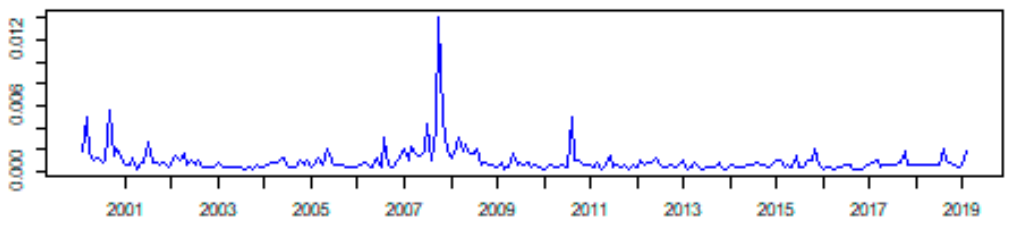

TPV of NZX 50 Index

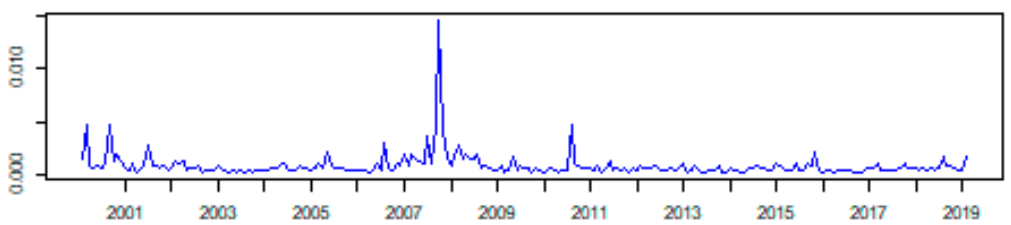

Figure 5. Integrated volatility measures-NZX 50. Notes: Figure 5 displays the volatility movements of the NZX 50. See the notes in Figure 2.

RV of Shanghai Composite Index

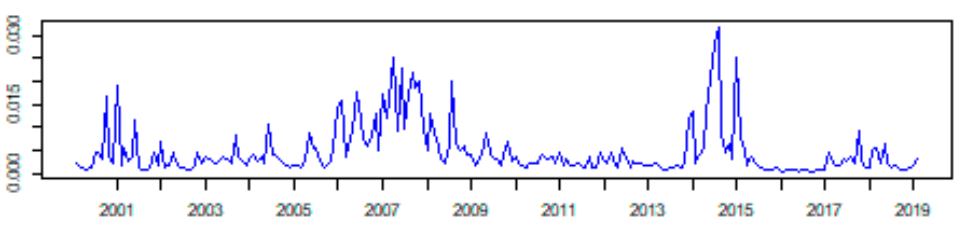

BPV of Shanghai Composite Index

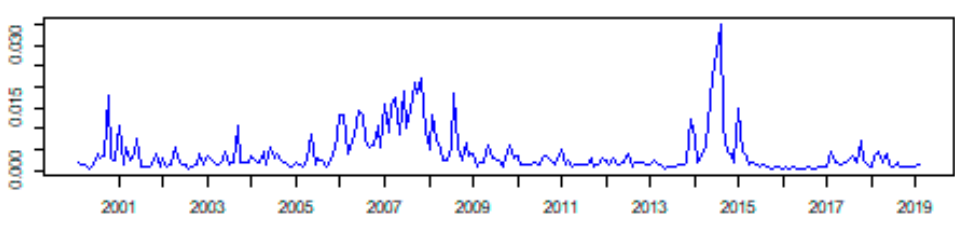

TPV of Shanghai Composite Index

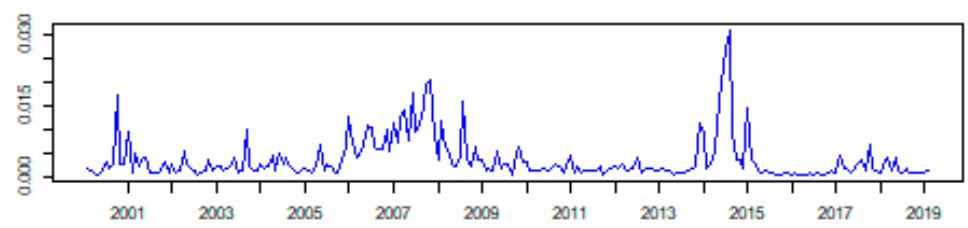

Figure 6. Integrated volatility measures-Shanghai Composite. Notes: Figure 6 displays the volatility movements of the Shanghai Composite. See the notes in Figure 2. 
RV of Nifty 50 Index

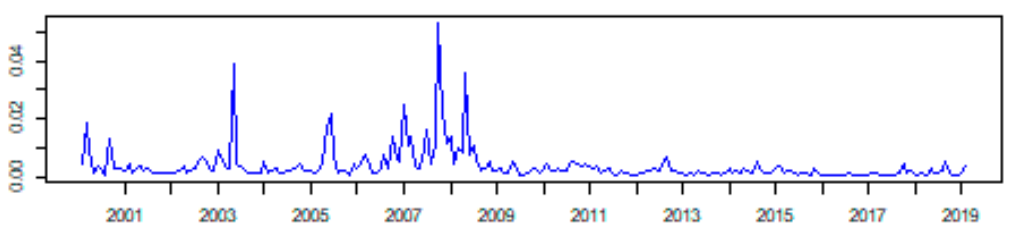

BPV of Nifty 50 Index

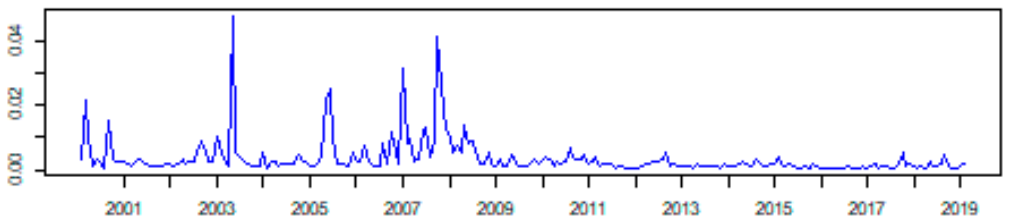

TPV of Nifty 50 Index

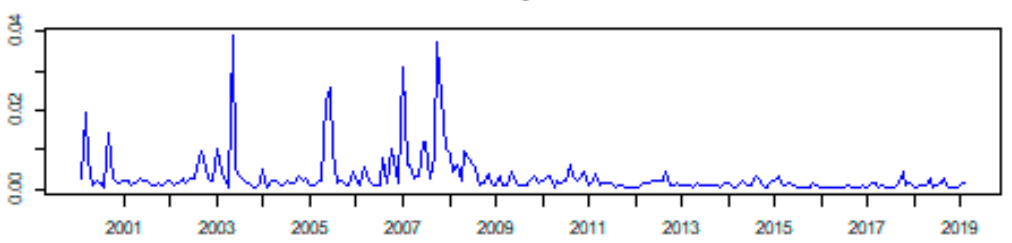

Figure 7. Integrated volatility measures-Nifty50. Notes: Figure 7 displays the volatility movements of the Nifty50. See the notes in Figure 2.
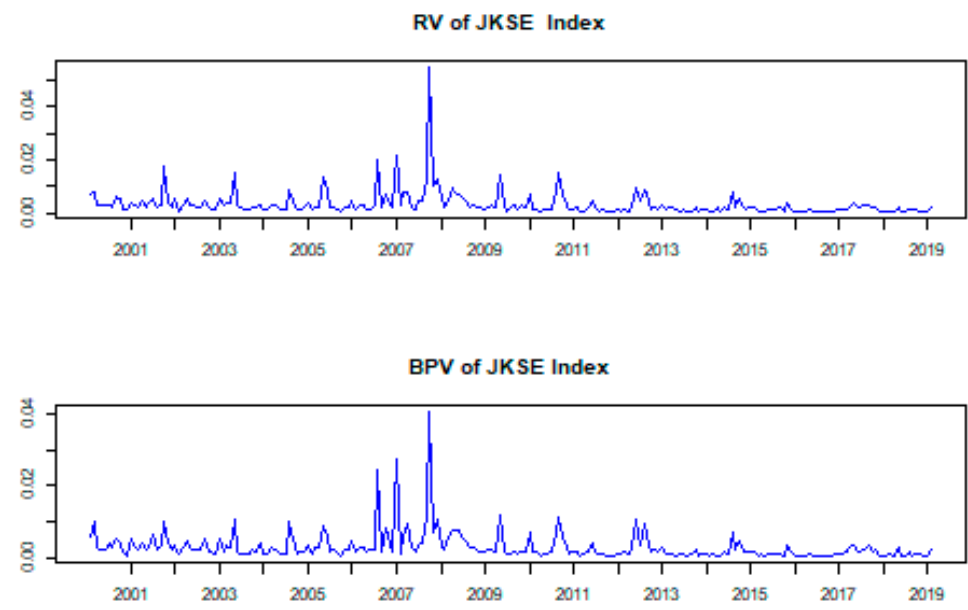

TPV of JKSE Index

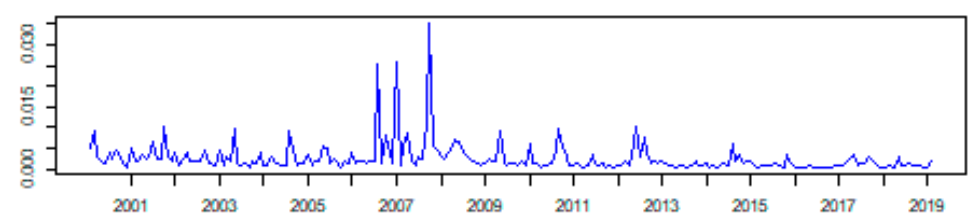

Figure 8. Integrated volatility measures-JKSE. Notes: Figure 8 displays the volatility movements of the JKSE. See the notes in Figure 2. 
RV of KSE-100 Index

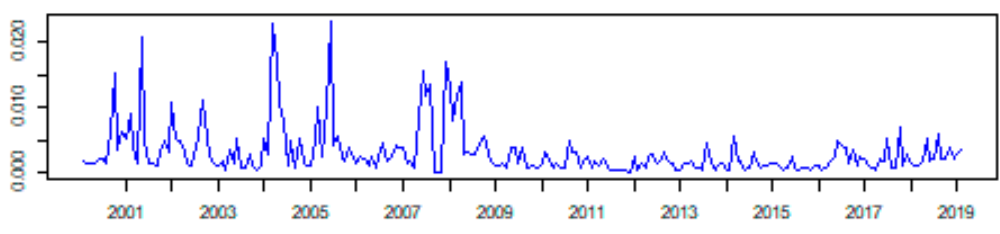

BPV of KSE-100 Index

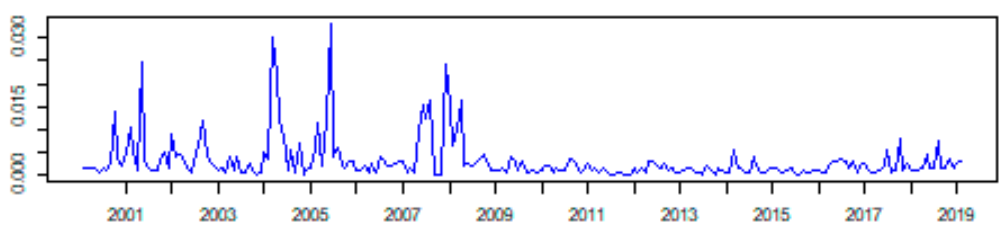

TPV of KSE-100 Index

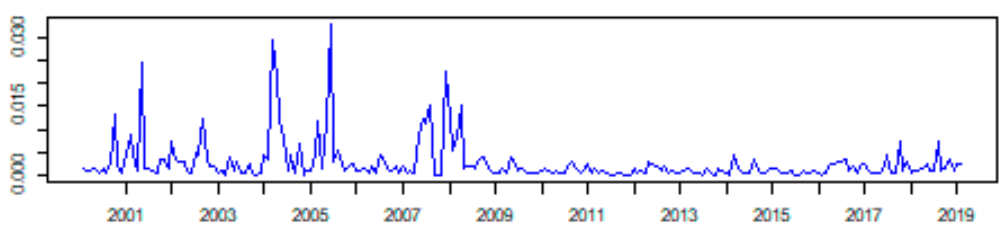

Figure 9. Integrated volatility measures-KSE-100. Notes: Figure 9 displays the volatility movements of the KSE-100. See the notes in Figure 2.
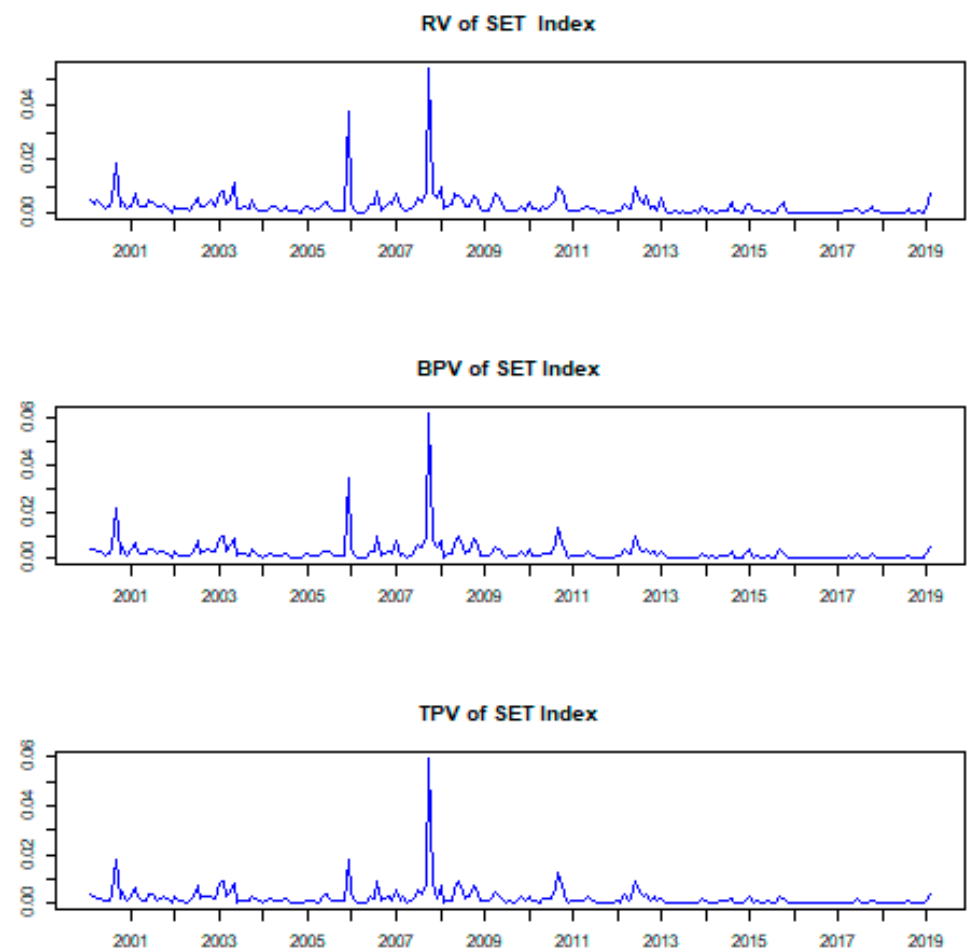

Figure 10. Integrated volatility measures-SET Index. Notes: Figure 10 displays the volatility movements of the SET Index. See the notes in Figure 2. 


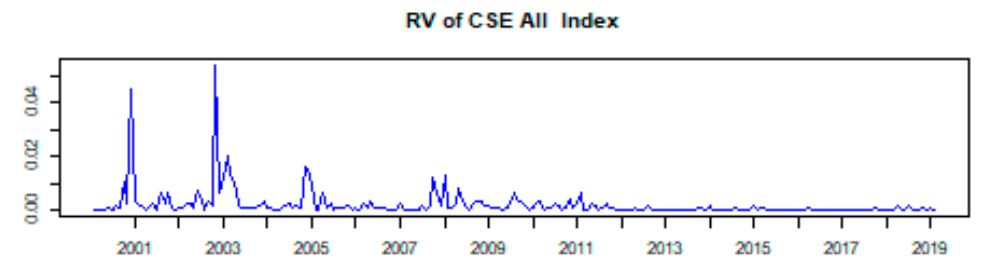

BPV of CSE All Index

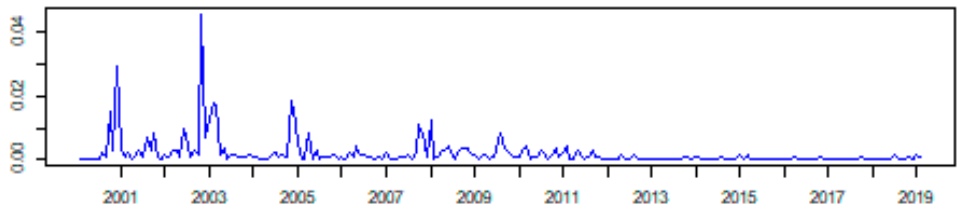

TPV of CSE All Index

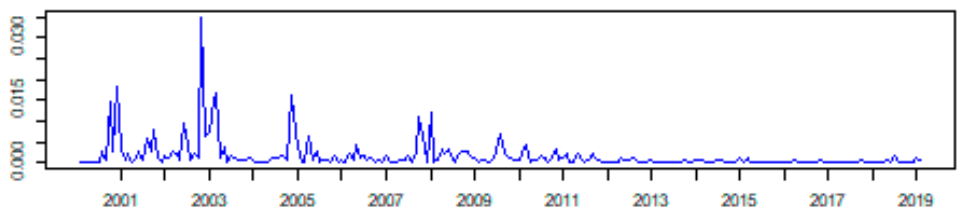

Figure 11. Integrated volatility measures-CSE All. Notes: Figure 11 displays the volatility movements of the CSE All. See the notes in Figure 2.

Table 4 shows the monthly volatility during jump periods for selected equity markets. First, volatility is estimated based on significant jumps. The volatility of positive and negative jumps is separated from total realized volatility.

In developed markets, the jump component shows a considerable amount of volatility in total realized volatility for all markets. However, volatility in negative jumps is higher than volatility in all jumps and volatility in positive jumps in developed markets except for with the Hang Seng, where volatility in positive jumps is higher than volatility in negative jumps. This pattern of high volatility for negative jumps is also consistent across emerging markets except the Nifty50 and CSE All index, where volatility in positive jumps is higher than in negative jumps. However, on average, total realized volatility and jumps-based volatility are larger for emerging markets than developed markets.

Table 4. Average variation due to jump component at a 5\% significance level (gives the descriptive statistics of jump volatility. Mean, standard deviation, min, and max values are all in terms of $10^{-3}$ ).

\begin{tabular}{ccccccccc}
\hline $\begin{array}{c}\text { Stock } \\
\text { Markets }\end{array}$ & $\begin{array}{c}\text { Jumping } \\
\text { Volatility }\end{array}$ & Jumps (n) & Mean & $\begin{array}{c}\text { Standard } \\
\text { Deviation }\end{array}$ & Minimum & Maximum & Kurtosis & Skewness \\
\hline \multirow{2}{*}{ S\&P ASX } & JV & 62 & 0.5221 & 0.5005 & 0.0032 & 2.1914 & 2.7766 \\
200 & PJV & 32 & 0.3765 & 0.3574 & 0.0032 & 1.5698 & 3.0047 & 1.7027 \\
& NJV & 27 & 0.6947 & 0.5911 & 0.0311 & 2.1914 & 1.1230 & 1.3516 \\
\hline \multirow{3}{*}{ Hang Seng } & JV & 71 & 1.3341 & 1.8391 & 0.1259 & 11.9661 & 18.5439 & 4.0233 \\
& PJV & 43 & 1.3845 & 2.1349 & 0.1259 & 11.9661 & 16.1284 & 3.8601 \\
& NJV & 28 & 1.2566 & 1.2917 & 0.1286 & 6.9190 & 13.9425 & 3.3268 \\
\hline \multirow{2}{*}{ Nikkei225 } & JV & 56 & 1.5360 & 1.8130 & 0.0012 & 8.3438 & 4.3579 & 2.1030 \\
& PJV & 33 & 1.3843 & 1.6807 & 0.1586 & 7.2191 & 4.1437 & 2.0988 \\
& NJV & 23 & 1.7537 & 2.0062 & 0.0012 & 8.3438 & 4.9369 & 2.1477 \\
\hline \multirow{2}{*}{ NZX 50 } & JV & 58 & 0.3423 & 0.4204 & 0.0106 & 2.4044 & 9.8693 & 2.8173 \\
& PJV & 32 & 0.2248 & 0.2674 & 0.0106 & 1.2783 & 8.6934 & 2.8753 \\
& NJV & 26 & 0.4870 & 0.5244 & 0.0243 & 2.4044 & 6.4010 & 2.3138 \\
\hline
\end{tabular}


Table 4. Cont.

\begin{tabular}{|c|c|c|c|c|c|c|c|c|}
\hline $\begin{array}{c}\text { Stock } \\
\text { Markets }\end{array}$ & $\begin{array}{l}\text { Jumping } \\
\text { Volatility }\end{array}$ & Jumps (n) & Mean & $\begin{array}{l}\text { Standard } \\
\text { Deviation }\end{array}$ & Minimum & Maximum & Kurtosis & Skewness \\
\hline \multirow{3}{*}{$\begin{array}{l}\text { Shanghai } \\
\text { Composite }\end{array}$} & JV & 93 & 1.9444 & 2.1683 & 0.1199 & 10.9971 & 6.2757 & 2.3618 \\
\hline & PJV & 41 & 1.8759 & 2.1943 & 0.1199 & 10.9740 & 7.5715 & 2.5677 \\
\hline & NJV & 52 & 1.9984 & 2.1676 & 0.1579 & 10.9971 & 6.0724 & 2.2749 \\
\hline \multirow{3}{*}{ Nifty50 } & JV & 63 & 1.4304 & 3.3792 & 0.0511 & 25.9597 & 48.0811 & 6.6383 \\
\hline & PJV & 38 & 1.5502 & 4.2256 & 0.0511 & 25.9597 & 32.1919 & 5.5233 \\
\hline & NJV & 23 & 1.2325 & 1.0230 & 0.1213 & 4.0245 & 1.9210 & 1.5553 \\
\hline \multirow{3}{*}{ JKSE } & JV & 67 & 1.5593 & 2.8102 & 0.0761 & 19.5782 & 26.2145 & 4.6318 \\
\hline & PJV & 41 & 1.0867 & 1.4862 & 0.0761 & 8.2438 & 13.2699 & 3.2588 \\
\hline & NJV & 26 & 2.3046 & 4.0461 & 0.2385 & 19.5782 & 13.8387 & 3.5188 \\
\hline \multirow{3}{*}{ KSE-100 } & JV & 73 & 0.9959 & 1.0711 & 0.0001 & 5.6903 & 5.2415 & 2.1014 \\
\hline & PJV & 51 & 0.7395 & 0.7675 & 0.0001 & 3.3940 & 4.3766 & 2.0441 \\
\hline & NJV & 17 & 1.7651 & 1.4578 & 0.2410 & 5.6903 & 1.9721 & 1.3910 \\
\hline \multirow{3}{*}{ SET Index } & JV & 77 & 1.0861 & 2.3810 & 0.0454 & 20.3652 & 59.0289 & 7.3028 \\
\hline & PJV & 49 & 0.7889 & 0.7984 & 0.0579 & 4.1480 & 5.9939 & 2.1599 \\
\hline & NJV & 27 & 1.6255 & 3.8352 & 0.0454 & 20.3652 & 24.2577 & 4.8260 \\
\hline \multirow{3}{*}{ CSE All } & JV & 100 & 0.8958 & 2.9551 & -0.3937 & 27.0898 & 64.1616 & 7.5430 \\
\hline & PJV & 59 & 1.0205 & 3.6129 & 0.0275 & 27.0898 & 48.8064 & 6.7857 \\
\hline & NJV & 36 & 0.8407 & 1.6953 & 0.0160 & 9.6081 & 21.3262 & 4.3165 \\
\hline
\end{tabular}

Table 5 shows the ratio of jump variations to total variations. The highest ratio is found in the Shanghai Composite Index. The minimum overall ratio is found for the S\&P ASX 200 index. The ratio of positive jump variation to total variation is maximum for the Hang Seng index and minimum for the S\&P ASX 200 index. The ratio of positive variation due to negative jump to total variation is maximum for the Nifty50 index and minimum for the NZX 50. When comparing developed and emerging markets, on average the ratio of jump variations to total variations is higher in emerging markets, Similarly, the ratio of variation during negative jump periods to total variation is also higher for emerging markets. It is concluded from the analysis that integrated volatility during a negative jump period is higher than integrated volatility during a positive jump period in both developed and emerging markets but this pattern is more pronounced in emerging markets.

Table 5. Average ratio of jump variation to total variations.

\begin{tabular}{cccc}
\hline & $\begin{array}{c}\text { The Average Ratio of } \\
\text { Jumps Variations to } \\
\text { Total Variations }\end{array}$ & $\begin{array}{c}\text { The Average Ratio of } \\
\text { Positive Jumps } \\
\text { Variations to Total } \\
\text { Variations }\end{array}$ & $\begin{array}{c}\text { The Ratio of } \\
\text { Negative Jumps } \\
\text { Variations to Total } \\
\text { Variations }\end{array}$ \\
\hline S\&P ASX 200 & $32.56 \%$ & $33.17 \%$ & $36.04 \%$ \\
Hang Seng & $41.34 \%$ & $44.12 \%$ & $37.08 \%$ \\
Nikkei225 & $39.86 \%$ & $42.47 \%$ & $36.13 \%$ \\
NZX 50 & $33.94 \%$ & $34.12 \%$ & $33.72 \%$ \\
Shanghai Composite & $41.82 \%$ & $43.20 \%$ & $40.73 \%$ \\
Nifty50 & $39.55 \%$ & $38.23 \%$ & $45.53 \%$ \\
JKSE & $36.60 \%$ & $33.85 \%$ & $40.94 \%$ \\
KSE-100 & $37.03 \%$ & $38.93 \%$ & $44.11 \%$ \\
SET Index & $39.34 \%$ & $41.81 \%$ & $36.71 \%$ \\
CSE All & $38.99 \%$ & $39.97 \%$ & $44.11 \%$ \\
\hline
\end{tabular}

\section{Discussion}

Our results are in line with those of (Ait-Sahalia 2004; Amaya and Vasquez 2011; Apergis and Apergis 2020; Baker et al. 2020; Dutta et al. 2020; Eraker et al. 2003; Odusami 2021; Sharif et al. 2020; Zhang et al. 2020). 
Zhang et al. (2020) conducted a study on the Chinese stock market, an emerging market, and emerging markets are mostly speculative due to the availability of a limited number of shares for trading in stock markets and the increasing role of institutional investors who act as noise traders. Therefore, they expected more jumps to occur in emerging markets. We found similar results of more jumps in emerging markets than developed markets.

Eraker et al. (2003) found evidence for jump returns and volatility. Similarly, Aitt-Sahalia (2004) also documented that jumps play a vital role in asset returns. Amaya and Vasquez (2011) suggest that positive jumps raise the prices of securities; therefore a risk-averse investor prefers positive jumps over a negative jump. Dutta et al. (2020) suggested including jumps to developed a more reliable model for volatility and for asset pricing. We also found that jumps play a crucial role in asset returns. Our study provides a very important piece of information to investors in developed and emerging markets to earn maximum returns during jump periods. During jump periods, investors can earn the highest returns by investing in more volatile markets in developed markets. Whereas investors in emerging markets can earn the highest returns during jump periods by investing in averagely volatile markets.

Baker et al. (2020) investigated the potential causes of the unusual reaction of the US stock market to the COVID-19 pandemic. He found that the COVID-19 pandemic has had a much more significant impact on the US stock market than others. Sharif et al. (2020) investigated the relationship between COVID-19, the stock market, geopolitical risk, and economic policy uncertainty. Analysis has shown that COVID-19 and oil price shocks have been found to have an impact on geopolitical risk levels, economic policy uncertainty, and stock market volatility. Apergis and Apergis (2020) analyzed the impact of the COVID-19 pandemic on the returns and volatility of the Chinese stock market. The analysis shows that COVID-19 has had a significant negative impact on stock returns and a significant positive effect on volatility. Odusami (2021) observed asymmetry in the distribution of jumps, with a higher magnitude of negative jumps than positive jumps. We also found similar results in our analysis; we found that the magnitude of big negative jumps is larger than the magnitude of big positive jumps, and this pattern is consistent for both developed and emerging markets. However, the pattern is much higher in emerging markets as compared with developed markets. Moreover, emerging markets show higher integrated volatility than developed markets. We observed that integrated volatility during the negative jump period is higher than integrated volatility during the positive jump period in both developed and emerging markets. However, this pattern is more pronounced in emerging markets. We note that all stock markets have volatility during financial crises. Most of the stock markets had their highest volatility in the 2008 crisis period.

\section{Concluding Remarks}

The purpose of this study is to examine whether jumps matter in equity market returns and integrated volatility. To accomplish the goal, we first determined jumps in market returns for both developed and emerging equity markets in Asia, including the S\&P ASX 200, Hang Seng, Nikkei225, NZX 50, Shanghai Composite, Nifty50, JKSE, KSE-100, SET Index, and CSE All and disentangled the identified jumps into positive and negative jumps. We then computed both monthly average return and integrated realized volatility and compared them with monthly average returns and integrated realized volatility during positive and negative jump periods.

This paper uses the concept in an efficient capital market theory (Fama 1970) that security prices fully reflect all relevant information and bring stock markets towards efficiency and leave no room for investors to earn excess returns. However, sometimes there exist abnormal movements or large discontinuous changes in stock prices that are infrequent but large. These extreme movements are known as jumps associated with the arrival of unexpected new information (Ferriani and Zoi 2020; Jiang and Zhu 2017; Sun and Gao 2020). Jumps capture all types of information, regardless of whether it is 
public or private information, including insider trading. Since risk-averse investors prefer positive jumps over negative jumps as positive jumps raise stock prices, stocks with more negative jumps should receive a higher premium than those with more positive jumps (Amaya and Vasquez 2011).

We then used the swap variance $(\mathrm{SwV})$ approach developed by Jiang and Oomen (2008) to identify monthly jumps in the equity prices from both developed and emerging markets from February 2001 to February 2020. Further, the method developed by Andersen et al. (2007) was used to separate the volatility of the jump component from the total realized volatility.

Our analysis shows that jumps matter in both equity market returns and integrated volatility. We find that jumps arise in all equity markets; however, developed markets have fewer jumps relative to emerging markets. Furthermore, in all markets, positive jumps occur more frequently than negative jumps. Moreover, the magnitude of negative jumps is larger than that of positive jumps in both big and small jumps categories in emerging markets. However, the magnitude of negative jumps is larger than positive jumps only in the big jumps category for the developed market.

When average monthly continuous returns are compared with average monthly returns during jump periods, we observe that average monthly returns are higher than continuous returns during jump periods. In emerging markets, the market with average volatility earns higher returns during jump periods, whereas highly volatile markets earn higher returns during jump periods in developed markets. Moreover, markets having lower continuous returns with higher volatility are more adversely affected during negative jump periods.

Furthermore, this study reveals that realized volatility consists of a significant portion of jumps-based volatility. Integrated volatility is high during periods of negative jumps compared with periods during positive jumps. This pattern is consistent in both developed and emerging markets. The average ratio of jump variations to total variation also shows considerable variations due to jumps, indicating total realized variation consisting of substantial variations due to jumps.

Our findings infer that emerging markets are not as efficient as developed markets, and thus, jumps occur more frequently in emerging markets. Investors in all markets prefer to get positive jumps to negative jumps so that stocks with more negative jumps should have a jump risk premium. Our findings also infer that investors should avoid markets with lower continuous returns and higher volatility due to adverse effects during negative jump periods. Investors in emerging markets perceive more serious negative information than in developed markets because integrated volatility is high during negative jumps compared with periods during positive jumps, and this pattern is more pronounced in emerging markets.

The implication of this study is for all types of investors for both developed and emerging markets. The findings in our study suggest individual investors and portfolio managers of developed emerging markets avoid investment in assets and markets that are too volatile and have lower returns because these assets and markets are adversely affected by negative jumps. However, this study encourages investors and portfolio managers to invest in highly volatile assets with positive jumps because it will enable investors to earn higher returns. Furthermore, for investors in developing markets, investment in the averagely volatile assets and markets is the most efficient investment during the positive jumps period. The implication is also very important for asset pricing theory as investors prefer positive jumps to negative jumps. Therefore, stocks with negative jumps should earn a premium compared to stocks with positive jumps. This is also an important factor in the consideration of investment. This study provides insights to academics, practitioners, and policymakers on the asymmetric effect of jumps in equity market returns and integrated volatility in the context of developed and emerging markets.

One of the limitations of our study is that our data have not covered the COVID19 period and our study is limited to Asian developed and emerging equity markets. 
Thus, future researchers could extend our study to cover the COVID-19 period and by including other markets in their study. Moreover, future research could consider using other techniques to estimate jumps, for example, the jump identification methods developed by Aït-Sahalia and Jacod (2009), Barndorff-Nielsen and Shephard (2006), and Lee and Mykland (2008). Most importantly, future studies could also incorporate jumps as a factor in asset pricing models.

Author Contributions: Conceptualization, H.Z. and A.H.; methodology, H.Z. and A.H.; software, H.Z. and A.H.; validation, H.Z., A.H., and W.-K.W.; formal analysis, H.Z. and A.H.; investigation, H.Z., A.H., and W.-K.W.; resources, H.Z., A.H., and W.-K.W.; data curation, H.Z. and A.H.; writingoriginal draft preparation, H.Z. and A.H.; project administration, H.Z., A.H., and W.-K.W.; funding acquisition, H.Z., A.H., and W.-K.W. All authors have read and agreed to the published version of the manuscript.

Funding: This research has been supported by Capital University of Science and Technology, Asia University, China Medical University Hospital, The Hang Seng University of Hong Kong, Research Grants Council (RGC) of Hong Kong (project number 12500915), and Ministry of Science and Technology (MOST, Project Numbers 106-2410-H-468-002 and 107-2410-H-468-002-MY3), Taiwan.

Institutional Review Board Statement: Not applicable.

Informed Consent Statement: Not applicable.

Data Availability Statement: Not applicable.

Acknowledgments: The authors thank Ralf Fendel, and the anonymous referees for their helpful comments which help to improve our manuscript significantly. The third author would like to thank Robert B. Mil-ler and Howard E. Thompson for their continuous guidance and encouragement.

Conflicts of Interest: The authors declare no conflict of interest.

\section{References}

Aït-Sahalia, Yacine. 2004. Disentangling diffusion from jumps. Journal of Financial Economics 74: 487-528. [CrossRef]

Aït-Sahalia, Yacine, and Thomas Robert Hurd. 2015. Portfolio choice in markets with contagion. Journal of Financial Econometrics 14: 1-28. [CrossRef]

Aït-Sahalia, Yacine, and Jean Jacod. 2009. Testing for jumps in a discretely observed process. The Annals of Statistics 37: 184-222. [CrossRef]

Aït-Sahalia, Yacine, and Jean Jacod. 2012. Analyzing the spectrum of asset returns: Jump and volatility components in high frequency data. Journal of Economic Literature 50: 1007-50. [CrossRef]

Amaya, Diego, and Aurelio Vasquez. 2011. Explaining Stock Returns with Intraday Jumps, Working paper. [CrossRef]

Andersen, Torben G., Tim Bollerslev, Francis X. Diebold, and Paul Labys. 2001. The distribution of realized exchange rate volatility. Journal of the American Statistical Association 96: 42-55. [CrossRef]

Andersen, Torben G., Tim Bollerslev, and Francis X. Diebold. 2003a. Some Like it Smooth, and Some Like it Rough: Untangling Continuous and Jump Components in Measuring, Modeling, and Forecasting Asset Return Volatility, Working paper. Duke University. [CrossRef]

Andersen, Torben G., Tim Bollerslev, Francis X. Diebold, and Paul Labys. 2003b. Modeling And Forecasting Realized Volatility. Econometrica 71: 579-625. [CrossRef]

Andersen, Torben G., Tim Bollerslev, and Francis X. Diebold. 2007. Roughing it up: Including jump components in the measurement, modeling, and forecasting of return volatility. Review of Economics and Statistics 89: 701-20. [CrossRef]

Andersen, Torben G., Dobrislav Dobrev, and Ernst Schaumburg. 2012. Jump-robust volatility estimation using nearest neighbor truncation. Journal of Econometrics 169: 75-93. [CrossRef]

Apergis, Nicholas, and Emmanuel Apergis. 2020. The role of Covid-19 for Chinese stock returns: Evidence from a GARCHX model. Asia-Pacific Journal of Accounting and Economics 27: 1-9. [CrossRef]

Back, Kerry. 1991. Asset pricing for general processes. Journal of Mathematical Economics 20: 371-95. [CrossRef]

Bajgrowicz, Pierre, Olivier Scaillet, and Adrien Treccani. 2016. Jumps in high-frequency data: Spurious detections, dynamics, and news. Management Science 62: 2198-217. [CrossRef]

Baker, Scott R., Nicholas Bloom, Steven J. Davis, Kyle Kost, Marco Sammon, and Tasaneeya Viratyosin. 2020. The unprecedented stock market reaction to COVID-19. Review of Asset Pricing Studies 10: 742-58. [CrossRef]

Barndorff-Nielsen, Ole E., and Neil Shephard. 2003. Realized power variation and stochastic volatility models. Bernoulli 9: $243-65$. [CrossRef]

Barndorff-Nielsen, Ole E., and Neil Shephard. 2004. Power and Bipower Variation with Stochastic Volatility and Jumps. Journal of Financial Econometrics 2: 1-37. [CrossRef] 
Barndorff-Nielsen, Ole E., and Neil Shephard. 2006. Econometrics of Testing for Jumps in Financial Economics Using Bipower Variation. Journal of Financial Econometrics 4: 1-30. [CrossRef]

Brownlees, Christian, Eulalia Nualart, and Yucheng Sun. 2020. On the estimation of integrated volatility in the presence of jumps and microstructure noise. Econometric Reviews 39: 991-1013. [CrossRef]

Buncic, Daniel, and Katja IM Gisler. 2017. The role of jumps and leverage in forecasting volatility in international equity markets. Journal of International Money and Finance 79: 1-19. [CrossRef]

Carr, Peter, and Liuren Wu. 2003. What Type of Process Underlies Options? A Simple Robust Test. Journal of Finance 58: 2581-610. [CrossRef]

Corradi, Valentina, Mervyn J. Silvapulle, and Norman R. Swanson. 2018. Testing for jumps and jump intensity path dependence. Journal of Econometrics 204: 248-67. [CrossRef]

Corsi, Fulvio, Davide Pirino, and Roberto Reno. 2010. Threshold bipower variation and the impact of jumps on volatility forecasting. Journal of Econometrics 159: 276-88. [CrossRef]

Duangin, Saowaluk, Woraphon Yamaka, Jirakom Sirisrisakulchai, and Songsak Sriboonchitta. 2018. Volatility Jump Detection in Thailand Stock Market. In International Symposium on Integrated Uncertainty in Knowledge Modelling and Decision Making. Cham: Springer, Volume 10758, pp. 445-56. [CrossRef]

Dutta, Anupam, Elie Bouri, and David Roubaud. 2020. Modelling the volatility of crude oil returns: Jumps and volatility forecasts. International Journal of Finance and Economics 26: 889-97. [CrossRef]

Eraker, Bjørn, Michael Johannes, and Nicholas Polson. 2003. The Impact of Jumps in Volatility and Returns. Journal of Finance 58: 1269-300. [CrossRef]

Eugene F. Fama. 1970. Efficient Capital Markets: A Review of Theory and Empirical Work. The Journal of Finance 25: 383-417. [CrossRef]

Ferriani, Fabrizio, and Patrick Zoi. 2020. The dynamics of price jumps in the stock market: An empirical study on Europe and U.S. European Journal of Finance 26: 1-25. [CrossRef]

Huang, Xin, and George Tauchen. 2005. The relative contribution of jumps to total price variance. Journal of Financial Econometrics 3 : 456-99. [CrossRef]

Jiang, George J., and Roel CA Oomen. 2008. Testing for jumps when asset prices are observed with noise-a "swap variance" approach. Journal of Econometrics 144: 352-70. [CrossRef]

Jiang, George J., and Tong Yao. 2013. Stock Price Jumps and Cross-Sectional Return Predictability. Journal of Financial and Quantitative Analysis 48: 1519-44. [CrossRef]

Jiang, George J., and Kevin X. Zhu. 2017. Information Shocks and Short-Term Market Underreaction. Journal of Financial Economics 124: 43-64. [CrossRef]

Johannes, Michael. 2004. The statistical and economic role of jumps in continuous-time interest rate models. The Journal of Finance 59: 227-260. [CrossRef]

Kostrzewski, Maciej, and Jadwiga Kostrzewska. 2021. The Impact of Forecasting Jumps on Forecasting Electricity Prices. Energies 14: 336. [CrossRef]

Kongsilp, Worawuth, and Cesario Mateus. 2017. Volatility risk and stock return predictability on global financial crises. China Finance Review International. [CrossRef]

Lee, Suzanne S., and Jan Hannig. 2010. Detecting jumps from Lévy jump diffusion processes. Journal of Financial Economics 96: 271-90. [CrossRef]

Lee, Suzanne S., and Per A. Mykland. 2008. Jumps in financial markets: A new nonparametric test and jump dynamics. Review of Financial Studies 21: 2535-63. [CrossRef]

Lee, Suzanne S., and Per A. Mykland. 2012. Jumps in equilibrium prices and market microstructure noise. Journal of Econometrics 168: 396-406. [CrossRef]

Maneesoonthorn, Worapree, Gael M. Martin, and Catherine S. Forbes. 2020. High-frequency jump tests: Which test should we use? Journal of Econometrics 219: 478-87. [CrossRef]

Merton, Robert C. 1976. Option pricing when underlying stock returns are discontinuous. Journal of Financial Economics 3: 125-44. [CrossRef]

Neuberger, Anthony. 1994. The log contract. Journal of Portfolio Management 20: 74. [CrossRef]

Nguyen, Duc Binh Benno, and Marcel Prokopczuk. 2019. Jumps in commodity markets. Journal of Commodity Markets 13: 55-70. [CrossRef]

Odusami, Babatunde O. 2021. Volatility jumps and their determinants in REIT returns. Journal of Economics and Business 113: 105943. [CrossRef]

Pan, Jun. 2002. The jump-risk premia implicit in options: Evidence from an integrated time-series study. Journal of Financial Economics 63: 3-50. [CrossRef]

Podolskij, Mark, and Daniel Ziggel. 2010. New tests for jumps in semimartingale models. Statistical Inference for Stochastic Processes 13: 15-41. [CrossRef]

Sharif, Arshian, Chaker Aloui, and Larisa Yarovaya. 2020. COVID-19 pandemic, oil prices, stock market, geopolitical risk and policy uncertainty nexus in the US economy: Fresh evidence from the wavelet-based approach. International Review of Financial Analysis 70: 101496. [CrossRef] 
Sun, Bianxia, and Yang Gao. 2020. Market liquidity and macro announcement around intraday jumps: Evidence from Chinese stock index futures markets. Physica A: Statistical Mechanics and Its Applications 541: 123308. [CrossRef]

Uddin, Moshfique, Anup Chowdhury, Keith Anderson, and Kausik Chaudhuri. 2021. The effect of COVID-19 pandemic on global stock market volatility: Can economic strength help to manage the uncertainty? Journal of Business Research 128: 31-44. [CrossRef]

Wright, Jonathan H., and Hao Zhou. 2009. Bond risk premia and realized jump risk. Journal of Banking and Finance 33: $2333-45$. [CrossRef]

Zhang, Chuanhai, Zhi Liu, and Qiang Liu. 2020. Jumps at ultra-high frequency: Evidence from the Chinese stock market. Pacific Basin Finance Journal 101420. [CrossRef] 